\title{
Simulation of the mineral dust content over Western Africa from the event to the annual scale with the CHIMERE-DUST model
}

\author{
C. Schmechtig ${ }^{1}$, B. Marticorena ${ }^{1}$, B. Chatenet ${ }^{1}$, G. Bergametti ${ }^{1}$, J. L. Rajot $^{2}$, and A. Coman ${ }^{1}$ \\ ${ }^{1}$ LISA, UMR7583, CNRS, Universités Paris Est-Paris Diderot, Créteil, France \\ ${ }^{2}$ IRD-UMR 211 BIOEMCO, Niamey, Niger
}

Received: 17 December 2010 - Published in Atmos. Chem. Phys. Discuss.: 9 March 2011

Revised: 23 June 2011 - Accepted: 12 July 2011 - Published: 22 July 2011

\begin{abstract}
The chemistry and transport model CHIMEREDUST have been used to simulate the mineral dust cycle over the Sahara in 2006. Surface measurements deployed during the AMMA field campaign allow to test the capability of the model to correctly reproduce the atmospheric dust load and surface concentrations from the daily to the seasonal time-scale. The simulated monthly mean Aerosol Optical Depths (AOD) and surface concentrations are significantly correlated with the measured ones. The simulated daily concentrations and hourly AOD are in the same range of magnitude than the observed ones despite relatively high simulated dust emissions. The level of agreement between the simulations and the observations has been quantified at different time scales using statistical parameters classically used to evaluate air quality models. The capability of the model to reproduce the altitude of the dust transport was tested for two contrasted cases of low and high altitude transport. These results highlight the sensitivity of the simulations to the surface winds used as external forcing and the necessity to further constrain the dust mass budget at the regional scale.
\end{abstract}

\section{Introduction}

Mineral dust, mainly produced by the aeolian erosion occurring in arid and semiarid regions, represents about $40 \%$ of the aerosol mass emitted annually into the troposphere (IPCC, 2007). Most of the recent studies on mineral dust focus on their radiative effects and thus on their contribution to the expected climate changes. Indeed, during their transport in the atmosphere, mineral dust can cause either a positive

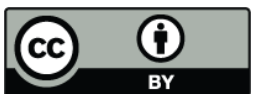

Correspondence to: B. Marticorena (marticorena@ lisa.univ-paris12.fr) or a negative radiative effect leading to a warming or cooling of the atmospheric layers (Sokolik et al., 2001), depending on both the surface characteristics and the optical properties of dust (Tegen and Lacis, 1996). These particles are also involved in chemical heterogeneous processes, interacting for example with nitrous (Manabe and Gotlieb, 1992; Wu and Okada, 1994), sulphured species (Dentener et al., 1996) or with other particles, modifying their chemical composition (Zhao et al., 1988), their size distribution and/or their number. Finally, when deposited in remote oceanic ecosystems, mineral dust can affect the biogeochemical cycle of some key nutrients or micronutrients such as iron or phosphorus (Jickells et al., 2005; Mahowald and al., 2008).

The whole dust cycle, i.e. the emission, transport and deposition, is strongly controlled, directly or indirectly, by meteorological parameters. Typically, dust emissions depends directly upon surface winds while in many transport regions, deposition is mainly controlled by precipitation. An illustration of the indirect influence of meteorological conditions on the mineral dust cycle is given by the increase of the mineral dust load (from 1957 to 1984) over the Sahel and the Tropical Atlantic Ocean during the Sahelian drought. During this period, N'Tchayi et al. (1994) showed that the number of days the horizontal visibility is affected by dust in Gao (Mali) increased from 20 days to 250 days per year. Simultaneously, the dust load reaching Barbados, in the western Atlantic Ocean, was multiplied by a factor of four (Prospero and Nees, 1977, 1986). This increase has been attributed to the emergence of additional dust sources in the Sahel due to the decrease of the vegetation cover induced by the drought. Another example of the connection between the mineral dust cycle and the climate is the connection of the inter-annual variations of dust transport from the Sahara-Sahel region towards the Mediterranean Sea and the Atlantic Ocean with the North Atlantic Oscillation Index (Moulin et al., 1997). As a

Published by Copernicus Publications on behalf of the European Geosciences Union. 
result, climatic changes of anthropogenic or natural origins are expected to significantly impact dust emissions and in particular the localisation and intensity of the dust sources.

Because of the high spatial and temporal variability of the dust concentrations in the atmosphere, regional modelling is frequently used to represent the mineral dust cycle and to quantify their impacts. Indeed, if global climatic models tend to reproduce satisfyingly the order of magnitude of the dust load at the global scale and their seasonal cycle (Tegen and Fung, 1994; Ginoux et al., 2001), they do not capture the spatial and temporal variability of atmospheric dust contents at a daily scale or at an inter-annual scale. In addition, they generally fail in representing correctly the seasonal dust cycle of mineral dust over the Sahara and the Sahel (Yoshioka et al., 2005). Chemistry Transport Models (CTMs) forced by meteorological fields provided by global models (e.g. from the European Centre from Medium-range Weather Forecasts) are less sensitive to misrepresentation of the dynamics and better agree with observations (Guelle et al., 2000; Luo et al., 2003). However, their accuracy remains limited by their low horizontal and vertical resolutions.

Simulations based on better resolved mesoscale meteorological models (i.e. Tegen et al., 2006; Bouet et al., 2007; Heinold et al., 2007; Tulet et al., 2008; Bou Karam et al., 2009; Stanelle et al., 2010) allow a more accurate description of the dynamics processes involved in the mineral dust cycle. However, these modelling tools are time-consuming and thus are mainly used for the simulations of case-studies. As an example, Heinold et al. (2007) simulated two major Saharan dust outbreaks transported towards Europe in August and October 2001 with the LM-MUSCAT dust model while Bouet et al. (2007), simulated the surface measurements from the BoDEx Experiment with the RAMS (Regional Atmospheric Modelling System) model. More recently, Schepanski et al. (2009) investigated the Saharan dust transport and deposition toward the Atlantic Ocean based on three months of simulation with the LM-MUSCAT dust model.

Another advantage of these regional meteorological models is their capability to account for the impact of mineral dust direct radiative effect on dynamics processes. As an example, Tulet et al. (2008), with the MesoNH model, showed that mineral dust could significantly impact the vertical structure of the atmosphere. However, the sign and intensity of the feedback on the dust emissions are still very uncertain. Miller et al. (2004) estimated that this feedback induces a decrease of the global dust emission of $15 \%$. At the regional scale, Heinold et al. (2007) found that it is responsible for a reduction of the dust emissions that can reach $50 \%$ for the October 2001 event. On the opposite, Stanelle et al. (2010), with the COSMO-ART model, found an increase of the Saharan dust emissions of 16\% in March 2006 and $25 \%$ in June 2006. These differences are related to the way the radiative impact is estimated and thus on one hand on dust properties (size distribution, scattering and extinction properties) and distribution (dust load and vertical distribution) and on the other hand on the radiative computation (radiation scheme, inclusion or not of the short-wave effect, etc., ...).

An alternative to investigate longer time periods over a specific region is to use a regional CTM, i.e. a CTM externally forced by regional meteorological fields. One limitation of this approach is that it does not allow to account for the interactions between dust and dynamics. However, regarding present uncertainty on this feedback described above, the representation of this feedback may be an additional source of uncertainty in the simulation. Such modelling tools have been widely developed and used to perform 3-D regional simulations of the tropospheric chemical composition because chemical models are extremely time consuming. Developed on the basis of the CTM CHIMERE (Vautard et al., 2001; Bessagnet et al., 2004), the CHIMERE-DUST model, is a dust-dedicated modelling tool which allows performing multi-annual simulations with a relevant spatial and temporal scale. This model was tested for dust forecasting during the winter 2006, including the dry-season experimental phase (SOP0) of the international African Monsoon Multidisciplinary Analysis (AMMA) program (Menut et al., 2009). A detailed description of the model can be found in Menut et al. (2007) and is summarized in Sect. 2.1.

Using this model to investigate the variability of the mineral dust content over West Africa needs a careful evaluation of its capability to simulate the main characteristic of the dust distribution, from the emission intensity and source location to transport patterns with relevant observations. As highlighted by many authors (i.e. Jaenicke and Schütz, 1978; d'Almeida and Schütz, 1983) the size range respectively covered by the mass and the number dust size distributions are very different. As an example, using a size distribution typical of emission conditions (emission by an aluminosilicate silt soil type (ASS) under a wind friction velocity $U *$ of $55 \mathrm{~cm} \mathrm{~s}^{-1}$ derived from Alfaro and Gomes, 2001), Forêt et al. (2006) estimated that particles with diameters greater than $2 \mu \mathrm{m}$ represent $98 \%$ of the mass distribution while they account for only $12 \%$ of the number distribution. These differences in the contribution of the different size range to the mass and to the number distribution significantly impact the way 3-D models can be tested, validated or optimized against observations. Cakmur et al. (2006) tried to constrain the magnitude of the dust emissions by using multiple observational data sets. They showed that the magnitude of the dust cycle is very sensitive to the data set used as a constraint, if only one data set is chosen. Typically, the results of their optimization of the dust emissions showed that the dust "clay" fraction (dust size from $0.01 \mu \mathrm{m}$ to $1 \mu \mathrm{m}$ ) is mainly constrained by the AOD measurements, while surface concentration and deposition measurements determine the "silt" (dust size from $1 \mu \mathrm{m}$ to $10 \mu \mathrm{m}$ ). They indicate that a consensus optimal solution agreeing with all the observations can be identified when using a combination of different data sets. 
The data collected during the AMMA international program offered the opportunity to produce such a combination of observations. The main objective of the AMMA program is to improve our knowledge and understanding of the West African Monsoon (WAM) and its variability, with an emphasis on daily-to-interannual time scales (Redelsperger et al., 2006). In the framework of this program, a set of 3 groundbased measurement stations located between $13-14^{\circ} \mathrm{N}$, the so-called "Sahelian Dust Transect" (SDT), has been deployed during $3 \mathrm{yr}$. It includes measurements of the $\mathrm{PM}_{10}$ (Particulate Matter collected with a cut-off $50 \%=10 \mu \mathrm{m}$ in diameter) concentration at the surface and of the columnintegrated aerosol amount and properties, i.e. the aerosol optical depth (Marticorena et al., 2010).

In this study, we compare the simulations performed with the CHIMERE-DUST model with the measurements performed in 2006, i.e. the year the intensive experimental phase of the AMMA program took place. After a presentation of the model, the measurements and the simulated dust emissions, the capability of the model to retrieve the seasonal dust cycle of the atmospheric dust load and the main characteristics of two typical dust events will be evaluated. This evaluation will be based on a comparison between the simulated and measured AOD and between concentrations simulated in the first layer of the model and the surface concentrations measured along the Sahelian Dust transect. The level of agreement between the simulations and the observations is quantified by statistical parameters, selected among those recommended to evaluate the reliability of air quality models.

\section{Tools and methods}

\subsection{CHIMERE-DUST model}

\subsubsection{Simulation domain and time period}

The simulation runs on a large domain $\left(10^{\circ} \mathrm{S}-60^{\circ} \mathrm{N}, 90^{\circ} \mathrm{W}-\right.$ $90^{\circ} \mathrm{E}$ ) including the North of Africa and the North Tropical Atlantic Ocean. This large domain allows us to investigate dust transport from the Sahara and the Sahel towards the Atlantic Ocean and/or the Mediterranean Sea. Because of its size, the horizontal domain has a horizontal grid resolution of $1^{\circ} \times 1^{\circ}$. Vertically, 15 levels are defined from the surface to $12 \mathrm{~km}$ (i.e. $200 \mathrm{hPa}$ ), the first layer of the model extending from 0 to $54 \mathrm{~m}$. Turbulent parameters as, $U *$, the friction velocity and, $h$, the boundary layer depth are estimated from the mean meteorological parameters (the wind components, $u$ and $v$, the temperature $T$, the specific humidity $q$, and the pressure $p$ ).
The transport model is that of the chemistry-transport model CHIMERE (Vautard et al., 2001; Bessagnet et al., 2004) currently used for boundary layer regional air pollution studies and forecasts. The horizontal transport is performed using the Van Leer scheme (Van Leer, 1979), the vertical transport with the first-order upwind scheme and the vertical mixing is estimated from the calculation of the bulk Richardson number as extensively described in Menut (2003). There is no added numerical horizontal diffusion considering that the transport scheme is diffusive enough. The dust simulations are performed with a one hour time-step for the whole year 2006. Typically, using a standard single processor machine, a one year simulation requires one week of computation.

\subsubsection{Dust emissions model}

Dust emissions are computed over the Sahara and the Arabian Peninsula using the dust emission model developed by Marticorena and Bergametti (1995). This model described the main step of the dust emission processes, i.e. the erosion threshold, the saltation flux and the dust emission efficiency, as a function of the surface properties (local surface roughness, soil size-distribution and soil texture) and of the wind friction velocity. The dust emission efficiency data set used for the simulations is the re-evaluation of the Marticorena et al.'s (1997) proposed by Laurent et al. (2008).

This emission model requires a mapping of surface properties (aeolian roughness lengths, soil types, soil textures). We use the surface database established according to Marticorena et al. (1997) and Callot et al. (2000) that includes the Sahara desert, but extended to the Arabian Peninsula, Middle East and Minor Asia. The spatial resolution of the data base is $1^{\circ} \times 1^{\circ}$, but, up to 5 different surface features (i.e. five combinations of soil type, surface roughness and fraction of erodible surface) can be distinguished in each square degree. This method operates like a Geographical Information System (GIS) by aggregating refined data deduced from various sources of information (topographical, geological maps, etc., ...) to a larger scale and more general information (Callot et al., 2000). The main support used for this mapping are the topographic maps from the French National Geographic Institut (IGN) available at various spatial scales (1/200 000; 1/500 000; 1/1 000 000) over the Sahara, the Soviet Military Topographic Maps (1/200 000; 1/500 000) over the Arabian Peninsula and the 1/250000 American Maps (J.O.G) from the Army Map Service of the US Army (1957-1958) for Minor Asia or the South eastern Sahara.

The wind friction velocity is computed as a function of the $10 \mathrm{~m}$ wind velocity and of the local surface roughness length assuming a logarithmic wind profile (i.e. neutral conditions) (Marticorena et al., 1997; Laurent et al., 2008). 
The impact of soil moisture was neglected since Laurent et al. (2008) found that the decrease of Saharan dust emissions by soil moisture never exceed $6 \%$ for the six year simulation period.

\subsubsection{Dust size distribution}

The size distribution of the emitted dust is computed according to the Alfaro and Gomes (2001) and Alfaro et al. (2004) model. The simulated dust size distribution is a combination of three log-normal distributions (Mode 1: $D_{\operatorname{med} 1}=1.5 \mu \mathrm{m}$, $\sigma_{1}=1.7 ;$ Mode $2: D_{\operatorname{med} 2}=6.7 \mu \mathrm{m}, \sigma_{2}=1.6 ;$ Mode 3: $D_{\text {med3 }}=14.2 \mu \mathrm{m}, \sigma_{3}=1.6$ ) whose relative proportions vary as a function of the soil type and of the wind friction velocity. Three different initial mass size distributions, resulting from different soil types and wind friction velocities taken from Alfaro and Gomes (2001) are given as examples on Fig. 1. The mass size distribution corresponding to a dust size distribution dominated by mode $1(83 \%)$ is produced from a coarse soil (Coarse Sand) for a high wind friction velocity $\left(U *=80 \mathrm{~cm} \mathrm{~s}^{-1}\right)$. The coarser dust size distribution, composed of $95 \%$ of the Mode 3, is produced from a fine soil (Alumino silicated silt) at low wind friction velocity $\left(U *=35 \mathrm{~cm} \mathrm{~s}^{-1}\right)$. An intermediate case with $10 \%$ of Mode 1, $18 \%$ of Mode 2 and $78 \%$ of Mode 3, produced by a coarse sand (CS) at a moderate wind friction velocity $\left(U *=40 \mathrm{~cm} \mathrm{~s}^{-1}\right)$, is also presented.

The vertical dust fluxes estimated from the dust emission efficiencies are then redistributed into the model size bins using a mass partition scheme. The dust size distribution is represented using 20 iso-log bins ranging from 0.01 to $24 \mu \mathrm{m}$. This number of bins is sufficiently high to avoid any bias in the simulation of the dust mass concentration, deposition and optical depth (Forêt et al., 2006).

\subsubsection{Dust deposition}

Dry deposition velocity is computed as a function of particle diameter following Venkatram and Pleim (1999). These authors proposed a slightly modified version of the formulation initially proposed by Wesely (1989). This dry deposition scheme introduces little differences in the magnitude of the deposition velocity but has the advantages to be consistent with the mass conservation equation and to be theoretically more accurate for large particles (Menut et al., 2007).

Wet removal processes includes two distinct mechanisms: rainout corresponds to the in-cloud scavenging of particles acting as condensation nuclei while wash-out refers to the below cloud scavenging of particles impacting by falling rain droplets. Due to their composition, dust particles are often considered as purely hydrophobic so no in-cloud scavenging is considered. This is also the case for CHIMEREDUST. Below-cloud scavenging is parameterized according to Slinn (1984) modified by Loosmore and Cederwall (2004) to account for larger scavenging in heavy rain events.

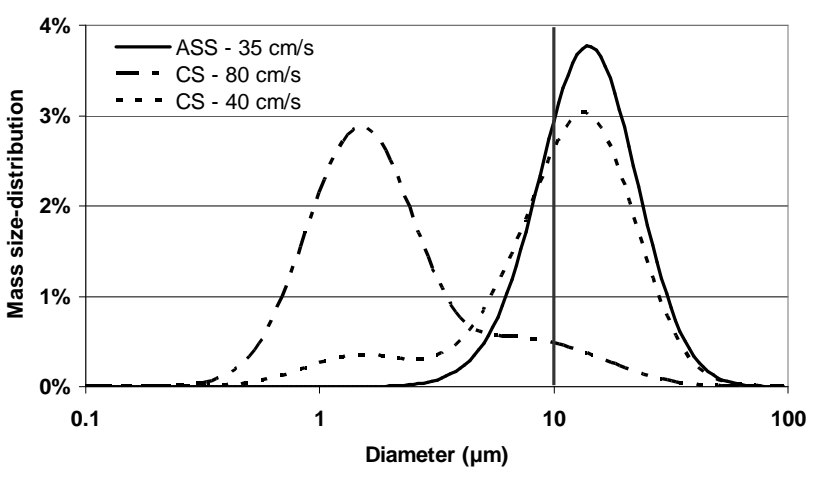

Fig. 1. Examples of relative dust mass size distributions from Alfaro and Gomes (2001) produced by two different soils (ASS: Alumino Silicated Silt; CS: Coarse Sand) for different wind friction velocity leading to different percentages $\left(0 \%\right.$ for ASS - $35 \mathrm{~cm} \mathrm{~s}^{-1} ; 83 \%$ for $\mathrm{CS}-80 \mathrm{~cm} \mathrm{~s}^{-1} ; 10 \%$ for $\left.\mathrm{CS}-40 \mathrm{~cm} \mathrm{~s}^{-1}\right)$ in the fine mode $\left(D_{\text {med } 1}=1.5 \mu \mathrm{m}, \sigma_{1}=1.7\right)$.

\subsubsection{Meteorological fields}

The model is forced by 3-D meteorological fields from the European Centre for Medium Weather Forecast (ECMWF). The used meteorological products are the "first guess" forecast products, i.e. almost similar to the operational analysis, at $1^{\circ} \times 1^{\circ}$ resolution and every $3 \mathrm{~h}$. This spatial resolution allows to perform the simulation over the selected large geographical domain during one year with an hourly temporal resolution.

It is now well recognized that the large scale meteorological models fail in reproducing the surface wind velocity in the Bodélé depression (Chad), one of the most active Saharan dust sources. Koren and Kaufman (2004) showed that NCEP (National Centre for Environmental Prediction) reanalysis winds underestimate by factor 2 the actual speed of the dust front in this region. Similarly, Bouet et al. (2007) found that ECMWF wind surface reanalysis are significantly underestimated compare to the surface wind locally measured in Chicha (Chad) in March 2005 during the the BoDEx 2005 experiment (Washington et al., 2006). The ECMWF $10 \mathrm{~m}$ surface winds have been compared to the surface wind measured at the meteorological station of Faya-Largeau, located at the North-Eastern edge of the Bodélé depression for the period January to March 2004, a period during which a sufficient number of observations is available both during day and night (Fig. 2). This period is known as a dusty period and several severe dust events occurred, in particular in early March (Menut et al., 2007). The comparison between the surface measurements and the ECMWF surface winds shows a similar temporal pattern. The frequency of wind velocity higher than the $10 \mathrm{~m}$-threshold wind velocity in the model $\left(\sim 7 \mathrm{~m} \mathrm{~s}^{-1}\right)$ is higher in the model $(50 \%)$ than in the measurements $(41 \%)$. However, the amplitude of the diurnal cycle is lower in the ECMWF winds than in the measurements, 


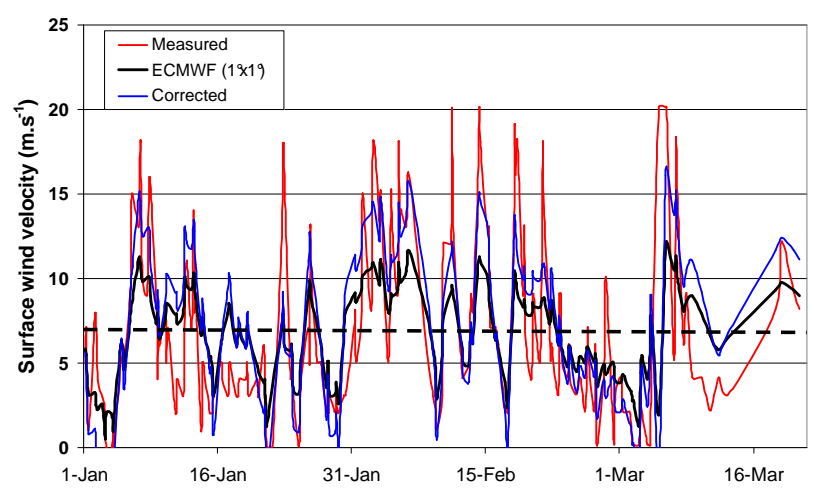

Fig. 2. $10 \mathrm{~m}$ wind velocity measured at the meteorological station of Faya-Largeau (Chad), $10 \mathrm{~m}$ wind velocity from the ECMWF operational products $\left(1^{\circ} \times 1^{\circ}\right)$ and $10 \mathrm{~m}$ wind velocity from ECMWF corrected using Eq. (3) in January-March 2004. The black dotted line corresponds to the minimum $10 \mathrm{~m}$ threshold wind velocity in the model $\left(\sim 7 \mathrm{~m} \mathrm{~s}^{-1}\right)$.

leading to a systematic underestimation of the highest winds. The measured surface wind velocities are as high as $20 \mathrm{~m} \mathrm{~s}^{-1}$ while surface wind velocities from ECMWF never exceed $12 \mathrm{~m} \mathrm{~s}^{-1}$. Such a bias on the high surface winds significantly impacts the simulated dust emission fluxes that are computed as a power 3 of the wind velocity.

Regarding the importance of the Bodélé depression as a dust source for the Sahelian region, a correction of the ECMWF surface wind was necessary. Ideally, it would be necessary to systematically evaluate the bias in the surface winds and its variability as a function of space and time in the region. Because there are no other available measurements in sufficient amount than those from the meteorological station of Faya-Largeau, the correction was established by fitting the modelled surface winds on the measured ones for January to March 2004 and applied to the grid meshes between $15^{\circ} \mathrm{N}-$ $19^{\circ} \mathrm{N}$ and $15^{\circ} \mathrm{E}-20^{\circ} \mathrm{E}$, corresponding to the location of the Bodélé depression. The following linear fitting was obtained (with $R^{2}=0.79 ; n=97$ ):

$$
\begin{aligned}
& 10 \mathrm{~m} \text { WindSpeed } \text { corrected }_{\text {. }}=-4,62707+1,7496 \\
& \times 10 \mathrm{~m} \text { WindSpeed } \\
& \text { ECMWF }
\end{aligned}
$$

Since this correction is not a simple ratio, it does not systematically lead to an increase of the surface wind velocities. In addition, it is only applied when the erosion threshold is exceeded. It increases the amplitude of the diurnal cycle, in agreement with measurements. It must be noted that this correction leads to surface winds that remain lower than those recorded at the station of Faya-Largeau in January-March 2004 (Fig. 2). This correction produces an increase of the surface winds only for initial surface winds higher than the erosion threshold. As a result, it does not change the occurrence of the dust events but only their intensity. The impact of this correction on the simulated dust emissions will be discussed later.

\subsubsection{Aerosol optical depth}

The aerosol optical depth at the reference solar wavelength of $550 \mathrm{~nm}$ is computed by a vertical integration of the simulated dust mass concentration $\mathrm{C}$ in each size bin weighted by the specific surface extinction mass, $\sigma$ calculated based on the Mie theory with a dust refractive index of (1.5-0.005i) (Moulin et al., 2001):

$$
\begin{aligned}
\mathrm{AOD} & =\int_{0}^{\mathrm{TOA}} \sigma_{e}(z) C(z) d z \\
\mathrm{AOD} & =\int_{0}^{\mathrm{TOA}} \sum_{i}^{\mathrm{Nbin}} \sigma_{e}(z, i) C(z, i) d z
\end{aligned}
$$

Because the extinction is maximum for particle diameter of about $0.55 \mu \mathrm{m}$, the most optically active particles in the dust mass size distribution comes from Mode 1. As a consequence, for the size distributions illustrated in Fig. 1 and for the same mass concentration, the finest size distribution would produce an AOD higher by a factor of 10 than the coarser one. In fact, once the mass proportion of Mode 1 exceeds $10 \%$, more than $50 \%$ of the AOD is due to particles smaller than $3 \mu \mathrm{m}$. As a result, AOD measurements in the visible range allow to test the capability of the model to simulate the most active dust particles on a radiative point of view. But they do not necessarily provide a sufficient level of constraint on the total atmospheric dust load and in particular on the contribution of the coarse dust particles to the total mass.

\subsection{The Sahelian Dust Transect}

The acquisition of quantitative information on the mineral dust content over the Sahel was the main objective of the deployment of the "Sahelian Dust Transect" (SDT) (Marticorena et al., 2010). This transect is composed of three stations aligned between 13 and $14^{\circ} \mathrm{N}$ along the main pathway of the Saharan and Sahelian dust toward the Atlantic Ocean, namely Banizoumbou (Niger, $13.54^{\circ} \mathrm{N}, 2.66^{\circ} \mathrm{E}$ ), Cinzana (Mali, $13.28^{\circ} \mathrm{N}, 5.93^{\circ} \mathrm{W}$ ) and $\mathrm{M}^{\prime}$ Bour (Senegal, $14.39^{\circ} \mathrm{N}$, $16.96^{\circ} \mathrm{W}$ ). Two of the three stations, Banizoumbou and $M^{\prime}$ 'Bour, have been implemented on pre-existing stations of the international network of sunphotometers AERONET (Aerosol Robotic Network) (Holben et al., 2001). The third station, Cinzana, has been included in the AERONET network in the framework of the AMMA project. The Aerosol Optical Depth (AOD) measured by the sunphotometer corresponds to the extinction due to aerosol integrated over the whole atmospheric column. This measurement is thus an indicator of the atmospheric content in optically active particles. Holben et al. (2001) indicate that the uncertainty on 


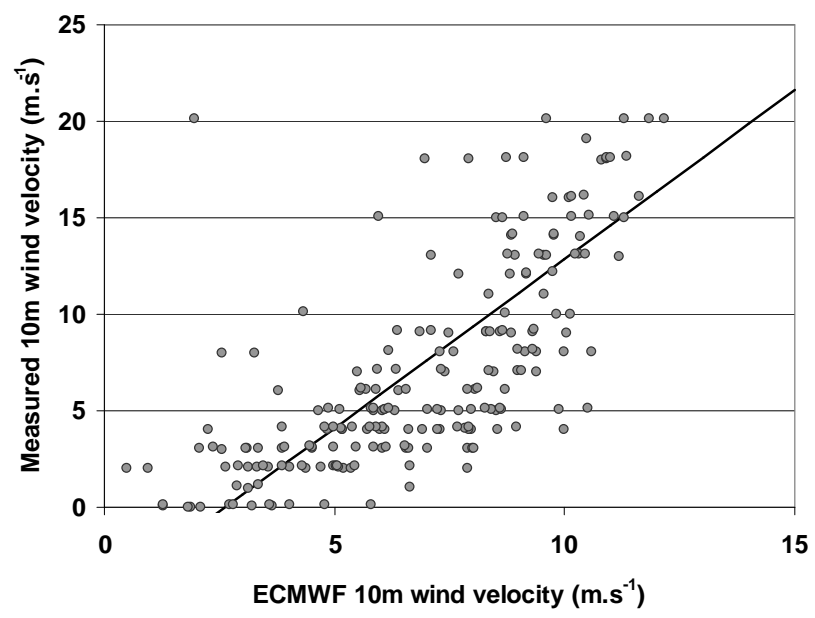

Fig. 3. $10 \mathrm{~m}$ wind velocity measured at the meteorological station of Faya-Largeau (Chad) as a function of the $10 \mathrm{~m}$ wind velocity from the ECMWF operational products for the square degree including the meteorological station of Faya Largeau $\left(R^{2}=0.7988, n=211\right)$.

the AOD retrieved from AERONET sunphotometers in the field was mainly due to calibration uncertainties and estimated the uncertainty to $0.01-0.02$, depending on the wavelength. AERONET sunphotometers are equipped with different channels allowing to compute the spectral dependence of the AOD, i.e. the Angström coefficient, $\alpha$. This spectral dependence is sensitive to the aerosol size. As mentioned above, desert dust is characterized by micron and supermicron particle size modes and thus exhibits very low $\alpha$ (close to 0 ), while $\alpha$ higher than 1 are observed when the aerosol mass size distribution is dominated by submicron particles (Holben et al., 2001). To discriminate the situations where dust clearly dominated the AOD, we selected only the values of AOD for which $\alpha$ (between 440 and $870 \mathrm{~nm}$ ) is lower than 0.4 (Note that in the following, the presented AODs are only for $\alpha$ lower than 0.4). In the model, the AOD is simulated at $550 \mathrm{~nm}$, it is thus compared to the AOD measured at the closest wavelength, $675 \mathrm{~nm}$. Because the $\alpha$ is close to 0 , the difference in the wavelength should not significantly affect the comparison. An estimation of the possible bias can be made by comparing the AOD measured at 675 and $440 \mathrm{~nm}$. For the three stations, the AOD at 675 and $440 \mathrm{~nm}$ associated with $\alpha<0.4$ are significantly correlated $\left(r^{2}=0.99\right)$ with slopes ranging from 1.04 in Cinzana to 1.06 in M'Bour. The difference induced by the comparison of modelled AODs at $550 \mathrm{~nm}$ and AODs measured at $675 \mathrm{~nm}$ should therefore not exceed $6 \%$.

Since January 2006, in addition to the AOD, the SDT provides a continuous monitoring of the atmospheric concentrations of Particulate Matter smaller than $10 \mu \mathrm{m}\left(\mathrm{PM}_{10}\right)$.They are measured at each station with a 5-min time step, using a Tapered Element Oscillating Microbalance (TEOM 1400A from Thermo Scientific) equipped with a $\mathrm{PM}_{10}$ inlet. The in- let is located at $\sim 9 \mathrm{~m}$ from the ground level in M'Bour and $\sim 6 \mathrm{~m}$ in Banizoumbou and Cinzana. Occasionally, aerosol vertical profiles were measured by a one-wavelength microlidar (Cavalieri et al., 2011). This instrument allows measurement of particulate concentrations ranging from a few micrograms to a few grams per cubic meters. In terms of sensitivity, the detection limit of the instrument is about $0.06 \mu \mathrm{g} \mathrm{m}^{-3}$ for a one hour sampling time.

As described in Marticorena et al. (2010) a selection of the data is applied to retain only the periods during which mineral dust are the main contributor to the measured $\mathrm{PM}_{10}$ mass. The procedure consists in excluding data from wind sectors that can bring other aerosol to the stations. This selection is critical for the M'Bour station which is located on the sea side, south of the town of M'Bour ( 180000-200000 inhabitants). As a result, data from wind sectors corresponding to transport from the sea or from the town of M'Bour have been excluded. This leads to a relatively high rejection during the wet season, where the monsoon flow promotes a westerly direction of the surface wind. Typically, on December or January, about $70 \%$ of the data are retained while their rejection rate can reach $95 \%$ at the maximum of the rain season (July and August). In Banizoumbou and Cinzana, during the dry season, the Harmattan regime characterized by northern and north-eastern surface winds generally prevails. However, to exclude possible incursion of the monsoon flow to the North during the dry season months (November to May) the data from this wind sector are excluded. From the selected data set, both the daily mean and median value are computed. The comparison between the mean and median allows to identify the days for which mesoscale convective systems produce short but intense local dust emissions, leading to a bias distribution of the data during the day (Marticorena et al., 2010).

\subsection{Model evaluation}

Satellite aerosol products are generally used to evaluate the way the model reproduces the source locations and extend. Due to the difficulty in retrieving quantitative AODs over bright surfaces, the most commonly used over the Sahara is the UV absorbing aerosol index initially derived from the Total Ozone Mapping Spectrometer (Herman et al., 1997; Torres et al., 1998) and now available from the recent OMI (Ozone Monitoring Instrument) instrument with spatial resolution of $\sim 100 \mathrm{~km}$ (Fig. 7). More recently, Hsu et al. $(2004,2006)$ developed an algorithm to derive the AOD at $490 \mathrm{~nm}$ from MODIS (Moderate Resolution Imaging Spectroradiometer) measurements, the so called "deep blue AOD". The UV aerosol index is known to be sensitive to the aerosol layer altitude (Torres et al. 1998; Hsu et al., 2004) and thus may not produce the higher indexes at the exact source. The main limitation of the deep blue AOD is that it is available for non cloudy conditions only. Both products will be used together to test the simulated dust source locations. 
The evaluation of regional dust model to properly simulate the atmospheric dust load is commonly evaluated by matching times series of simulated and measured AODs. This comparison allows to evaluate whether the range of simulated AODs is consistent with observations and whether the dynamics (timing and duration) of the dust events is correctly reproduced. Several distant measurements points allow to test the capability of the model to reproduce the spatial dynamics of the simulated dust plumes.

In addition to this qualitative approach, we tried here to give a quantitative estimation of the level of agreement between the simulation and the observations. Such quantitative evaluations based on statistical analysis are widely used for air quality models and in particular for the simulation of ozone concentrations (Borrego et al., 2008). Even if standard procedure or performance standards do not exist, some statistical indicators are commonly used. Combining different statistical parameters helps to understand models limitations and provides a support for model intercomparison (Borrego et al., 2008). A compilation of recommended statistical parameters has been provided by the United States Environmental Protection Agency (US EPA, 2007) but is also available at the European level (i.e. Borrego et al., 2008), with an estimation of the range of acceptability or of quality objectives for some of these parameters.

In addition to the classical parameters characterizing the linear fitting of the simulations versus observations (correlation coefficient, slope and intercept), statistical parameters recommended by the US EPA for the evaluation of $\mathrm{PM}_{2.5}$ concentration (particulate matter smaller than $2.5 \mu \mathrm{m}$ ) simulations have been selected. The normalized mean error (ranging from $0 \%$ to $+\infty$ ) quantifies the mean error of the model relative to the range of observations, while the normalized mean bias (ranging from $-100 \%$ to $+\infty$ ) allows to evaluate whether the model tends to over- or under- estimate the observed values. Normalized errors and bias can become very large when a minimum threshold on the measured value is not used. The mean fractional error (ranging from $-200 \%$ to $+200 \%$ ) and bias (ranging from 0 to $200 \%$ ) can be used as substitutes. Boylan and Russels (2006) suggest that these two parameters are the least biased and most robust indicators to evaluate the performance of particulate matter simulations.

The definition of all the selected statistical parameter are given below and the computed values are compiled in Table 1 .

Simple linear regression (least square regression):

$S=a O+b$

with $S$, the simulations, $O$, the observations, $a$, the slope of the regression and $b$ the intercept. $r$ is the correlation coefficient of the regression (and $r^{2}$ the determination coefficient) for $N$ data:
$r=\left[\sum_{i=1}^{N}\left(O_{i}-\bar{O}\right)\left(S_{i}-\bar{S}\right) / \sqrt{\sigma_{o} \sigma_{S}}\right]$

Normalized Mean Error:

$\mathrm{NME}=100 \% \sum_{i=1}^{N}\left|S_{i}-O_{i}\right| / \sum_{i=1}^{N} O_{i}$

Normalized mean bias:

$\mathrm{NMB}=100 \% \sum_{i=1}^{N}\left(S_{i}-O_{i}\right) / \sum_{i=1}^{N} O_{i}$

Mean fractional error:

$\mathrm{MFE}=\frac{2}{N} \sum_{i=1}^{N}\left(\left|S_{i}-O_{i}\right| /\left(S_{i}+O_{i}\right)\right) 100 \%$

Mean fractional bias:

$\mathrm{MFB}=\frac{2}{N} \sum_{i=1}^{N}\left(\left(S_{i}-O_{i}\right) /\left(S_{i}+O_{i}\right)\right) 100 \%$

Those parameters are widely used to evaluate air quality models and especially to intercompare the performances of different models. To our knowledge, this is the first time they are computed for regional mineral dust simulations. As a result, they cannot be used to compare our model with previously published studies, but this provides a support for future model intercomparisons. However to have some sort of reference on order of magnitude of these parameters, we report some recommendations and values for PM simulations by air quality models. Boylan and Russels (2006) suggested to consider that the level of accuracy considered to be close to the best a model can be expected to achieve, the so-called "model performance goal", for major components of $\mathrm{PM}_{2.5}$ has been met when the MFE is less or equal to $\sim 50 \%$ and the MFB is about $\pm 30 \%$. They also suggest that the level of accuracy that is considered to be acceptable for modeling applications for $\mathrm{PM}_{2.5}$ simulations, the so-called "model performance criteria" has been met when MFE is less than $\sim 75 \%$ and MFB lower than $\sim \pm 60$. These authors also compiled results from benchmark studies performed by a number of USA air quality models compared to observations from aerosol monitoring networks at the scale of episodes (i.e. a few days), months or seasons. The MFE reported for $\mathrm{PM}_{10}$ concentrations range from about 30 to $110 \%$, and the MFB between -100 and $+50 \%$ for $\mathrm{PM}_{10}$ concentrations ranging from 0 to $30 \mu \mathrm{g} \mathrm{m}^{-3}$. Values for "soil" dust are also reported (MFE between 50 and $200 \%$ and MFB between -50 and $\sim+175 \%$ ) but for very low concentrations $\left(0\right.$ to $2 \mu \mathrm{g} \mathrm{m}^{-3}$ ). These large errors and biases (compared to those recommended for gaseous compounds and especially for ozone) are largely explained by the unique and complicated aspects of measuring and modelling particulate matter (US EPA, 2007). 
Table 1. Statistical parameters quantifying the level of agreement (see definition in Sect. 2.3) between the simulations and the observations (Aerosol Optical Depths, AOD, or concentrations $\left(\mu \mathrm{g} \mathrm{m}^{-3}\right.$ ) for different time periods (monthly, daily, hourly): $n$ : number of data; $a, b, r$ and $r^{2}$ the slope, intercept, correlation coefficient and coefficient of determination of simple linear regression (note that regarding the number of data, all the computed correlation coefficient correspond to a probability lower than $0.01 \%$ ), NME the normalized mean error, NMB the normalized mean bias, MFE the mean fractional error, MFB, the mean fractional bias (*excluding monthly mean for January 2006 at the three stations and November and December means in Banizoumbou).

\begin{tabular}{lrrrrrrrrr}
\hline DATA & $n$ & $a$ & $b$ & $r$ & $r^{2}$ & $\begin{array}{r}\text { NME } \\
(\%)\end{array}$ & $\begin{array}{r}\text { NMB } \\
(\%)\end{array}$ & $\begin{array}{r}\text { MFE } \\
(\%)\end{array}$ & $\begin{array}{r}\text { MFB } \\
(\%)\end{array}$ \\
\hline Monthly AOD - All stations & & & & & & & & \\
Monthly AOD* - All stations & 36 & 1.56 & -0.30 & 0.57 & 0.33 & 51 & 7 & 57 & -31 \\
Monthly concentrations - All stations & 32 & 1.14 & -0.13 & 0.71 & 0.5 & 35 & 13 & 43 & -26 \\
Hourly AOD - Banizoumbou & 1938 & 0.76 & 32 & 0.51 & 0.26 & 75 & 6 & 68 & -14 \\
Hourly AOD - Cinzana & 1606 & 0.60 & 0.10 & 0.49 & 0.24 & 74 & -14 & 73 & -41 \\
Hourly AOD - M'Bour & 1899 & 0.39 & 0.30 & 0.65 & 0.42 & 91 & 2 & 74 & -33 \\
Daily concentrations - Banizoumbou & 333 & 0.30 & 105 & 0.55 & 0.30 & 96 & -3 & 82 & -49 \\
Daily concentrations - Cinzana & 352 & 0.70 & 48 & 0.58 & 0.33 & 75 & -36 & 86 & -53 \\
Daily concentrations M'Bour & 251 & 0.2 & 72 & 0.45 & 0.20 & 121 & 28 & 104 & -27 \\
\hline
\end{tabular}

\section{Results}

\subsection{Dust emissions}

\subsubsection{Annual dust emissions}

For the year 2006, the total dust emissions simulated over the Sahara are $2077 \mathrm{Tg}$. This estimate is quite high, since it is 3 times larger than the 6-yr average Saharan dust emissions of $670 \pm 70 \mathrm{Tg} \mathrm{an}^{-1}$ estimated by Laurent et al. (2008). Several elements in the computation of the dust emissions differ between these two estimates. First, the dust size range used in our simulation is larger than the one considered by Laurent et al. (2008). These authors provided an estimate of the Saharan dust emissions for particles smaller than $20 \mu \mathrm{m}$ in diameter. The size distribution from Alfaro and Gomes (2001) used in our simulations includes a coarse mode with a median diameter of $14.2 \mu \mathrm{m}$. When assuming the size distribution composed of $100 \%$ of this coarse mode, the fraction of the total dust mass with diameters higher than $20 \mu \mathrm{m}$ in diameter does not exceed $20 \%$. The difference between the two simulated annual dust emissions cannot thus be due to this factor only. Another element that could explain this difference is the fact that surface wind velocities for the Bodélé Depression have been corrected in order to better reproduce the high surface wind velocities responsible for the spring dust events. The annual dust emissions simulated for 2006 in the Bodélé Depression region are $227 \mathrm{Tg}$. The correction on the surface winds increases by a factor of 10 the emissions from the Bodélé depression. Despite this correction, dust emissions from this region represent $10 \%$ only of the total simulated Saharan dust emissions. This may be considered as relatively low for a region considered by some authors as the most active in the world (Prospero et al., 2002). However, these emissions are not high enough to explain the difference between the two estimations of Saharan dust emissions.

Finally, the observed difference in dust emissions can result from differences in the meteorological surface wind fields used in the two simulations. Laurent et al. (2008) used the climatological re-analysis ERA-40 produced by EMWF (not available for the year 2006), while the ECMWF operational products are used in our simulations. We thus compared the surface wind fields from the two data bases for one of the year simulated by Laurent et al. (2008), i.e. 2000 and for the grid meshes where dust emissions are computed. The comparison is made only for wind velocities higher than $7 \mathrm{~m} \mathrm{~s}^{-1}$ (i.e. $\sim$ the minimum modelled $10 \mathrm{~m}$ erosion threshold wind velocity) (Fig. 4). In both cases the proportion of surface winds exceeding the erosion threshold is very low, $4.5 \%$ for the ERA- 40 database and $8.1 \%$ for the operational forecast. However, this proportion is $80 \%$ higher in the ECMWF operational products than in the ERA-40 data base. So the occurrence of dust emission is potentially $80 \%$ higher. Moreover, the surface winds higher than the erosion thresholds are clearly higher in the ECMWF operational products than those from the ERA-40 (Fig. 4). As a result, the simulated dust emissions will be much higher, since dust emission fluxes are computed as a power 3 of the surface wind velocity.

Finally, the use of ECMWF operational products leads to more frequent and more intense dust emissions, which explains the differences between the simulated annual emissions and the one estimated by Laurent et al. (2008). Menut (2007) already highlighted the sensitivity of the dust emission simulations to the surface wind fields. For a 2.5 month period, he found a factor of 3 in the total emissions simulated with ECMWF operational products and with NCEP data base. Here, we found that different 


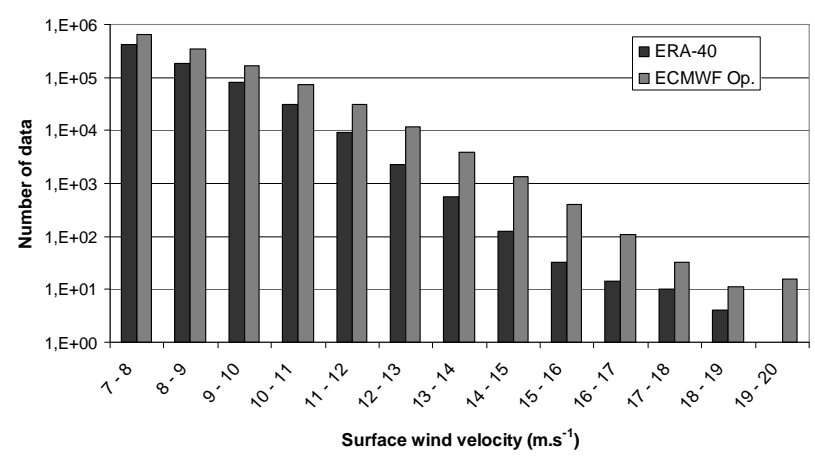

Fig. 4. Distribution of the surface wind velocity higher than $7 \mathrm{~m} \mathrm{~s}^{-1}$ for the year 2000 for the ERA-40 data base (dark grey) and for the ECMWF operational products (light grey) over the emission domain.

meteorological products (operational and re-analysis) from the same meteorological model can also induce a strong difference in the simulated dust emissions.

\subsubsection{Seasonality of the dust emissions}

The simulated dust emissions exhibit a clear seasonal cycle, in agreement with the works of d'Almeida (1986), Marticorena and Bergametti (1996) and Laurent et al. (2008) (Fig. 5). This seasonal cycle is characterized by a maximum of dust emissions during late winter and early spring, a secondary peak being simulated in summer. The minimum dust emissions are simulated for autumn. For 2006, the maximum monthly dust emission are simulated slightly earlier in the year than in Laurent et al. (2008), i.e. in February instead of March. Figure 6 shows that the seasonal cycle of the dust emission is associated with a change in their spatial distribution.

The winter months (January-February-March) (Fig. 6a) exhibit the highest Saharan dust emissions. They are mainly located in the North-east of the Sahara, i.e. in the North of Libya, with less intense dust emissions from sources located north of Mauritania and Mali and in the region of the Bodélé depression. Except for the Libyan sources, these regions were already the most active Saharan dust sources in the simulations performed by Laurent et al. (2008). The Libyan dust emissions are mainly related to an intense dust event simulated near the end of February. During this period, a dust plume is clearly observed on the UV aerosol index images (Herman et al., 1997; Torres et al., 1997) derived from the recent OMI instrument (Ozone Monitoring Instrument) (Fig. 7). The dust event occurs on 23 February at the frontier between Tunisia and Libya and progresses rapidly toward the East to reach Israel on 25 February. During this period, the North of Libya clearly appears as a relatively intense dust source from the seasonal mean AODs derived in the UV (Deep Blue AOD; Hsu et al., 2004, 2006) and OMI

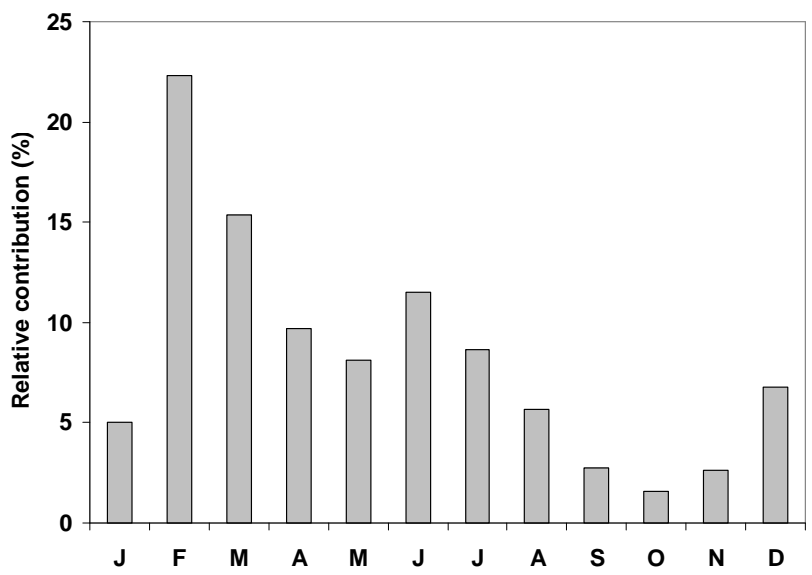

Fig. 5. Monthly relative contribution to the annual Saharan dust emissions simulated for 2006.

aerosol indexes (Fig. 8a). These observations tend to confirm that Libyan sources were active during the winter 2006, but probably overestimated in the simulation.

In spring (April to May), all possible dust sources are activated in the simulation (Fig. 6b). Compared to satellite observations, the simulation exhibits a comparable level of agreement and the same bias than in Laurent et al. (2008): almost all the simulated dust sources correspond either to significant Deep Blue AODs or OMI indexes but some of them appear as similarly overestimated or underestimated in terms of intensity (Fig. 8b). In terms of source location, a slightly better agreement is obtained with the Deep Blue AODs than with the OMI indexes, in particular in the North and Central Sahara. Even if intense emissions are simulated over the region of the Bodélé Depression, their relative intensity compared to the other sources regions is lower in the simulations than in the observations. Except in this region, almost no dust emissions are simulated south of $20^{\circ} \mathrm{N}$, while relatively high OMI indexes are recorded. Finally, the dust emissions simulated in the Western Sahara tends to be too intense compared to observations, as already noted by Laurent et al. (2008). Based on the satellite observations, this season should correspond to the period of the maximum of Saharan dust emissions. This suggests again that the winter dust emissions are overestimated in the model.

In the simulations, the summer months correspond to a secondary maximum of Saharan dust emissions (Fig. 8c) and to a shift of the dust sources to the South Western part of the Sahara, with very intense emissions along the West Coasts and North of Mauritania and Mali. Such intense dust emissions in the South-western Sahara are consistent with satellite observations, such a pattern being particularly evident from OMI indexes (Fig. 8c).

Autumn (October to December) is the period during which the simulated emissions are the lowest, the region of the Bodélé depression being almost the only intense simulated 
(a)

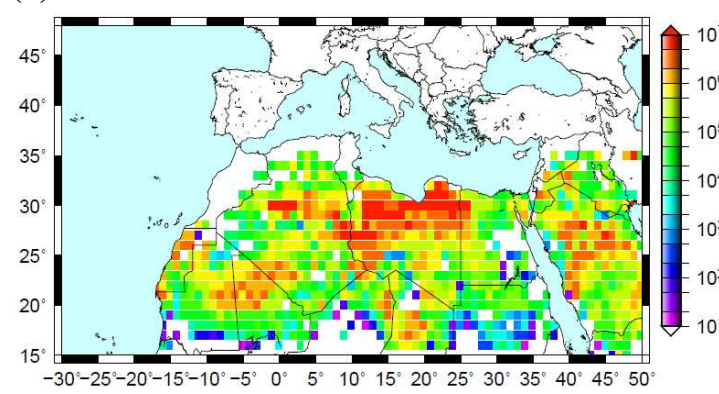

(c)

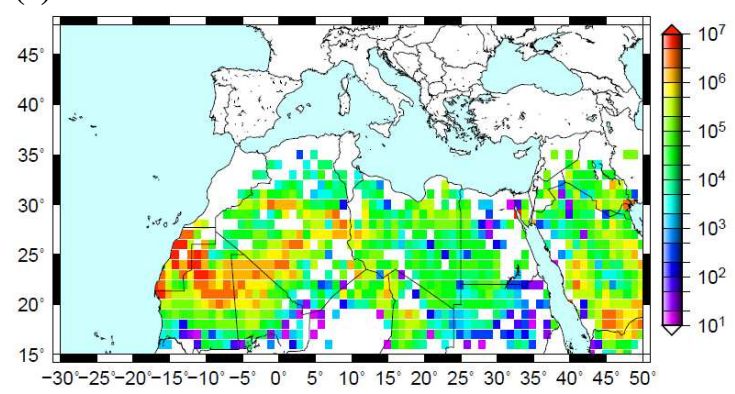

(b)

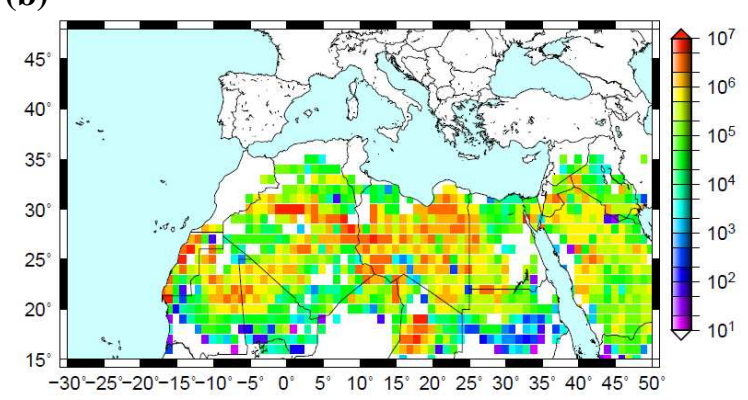

(d)

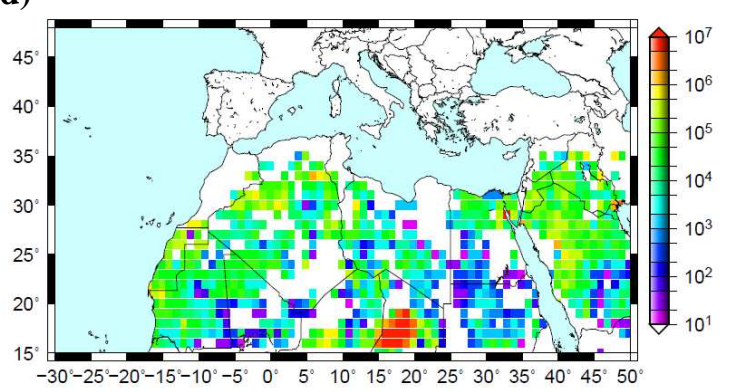

Fig. 6. Simulated dust emissions for (a) winter (January-February-March), (b) spring (April-May-June), (c) summer (July-AugustSeptember) and (d) autumn (October-November-December) in 2006.

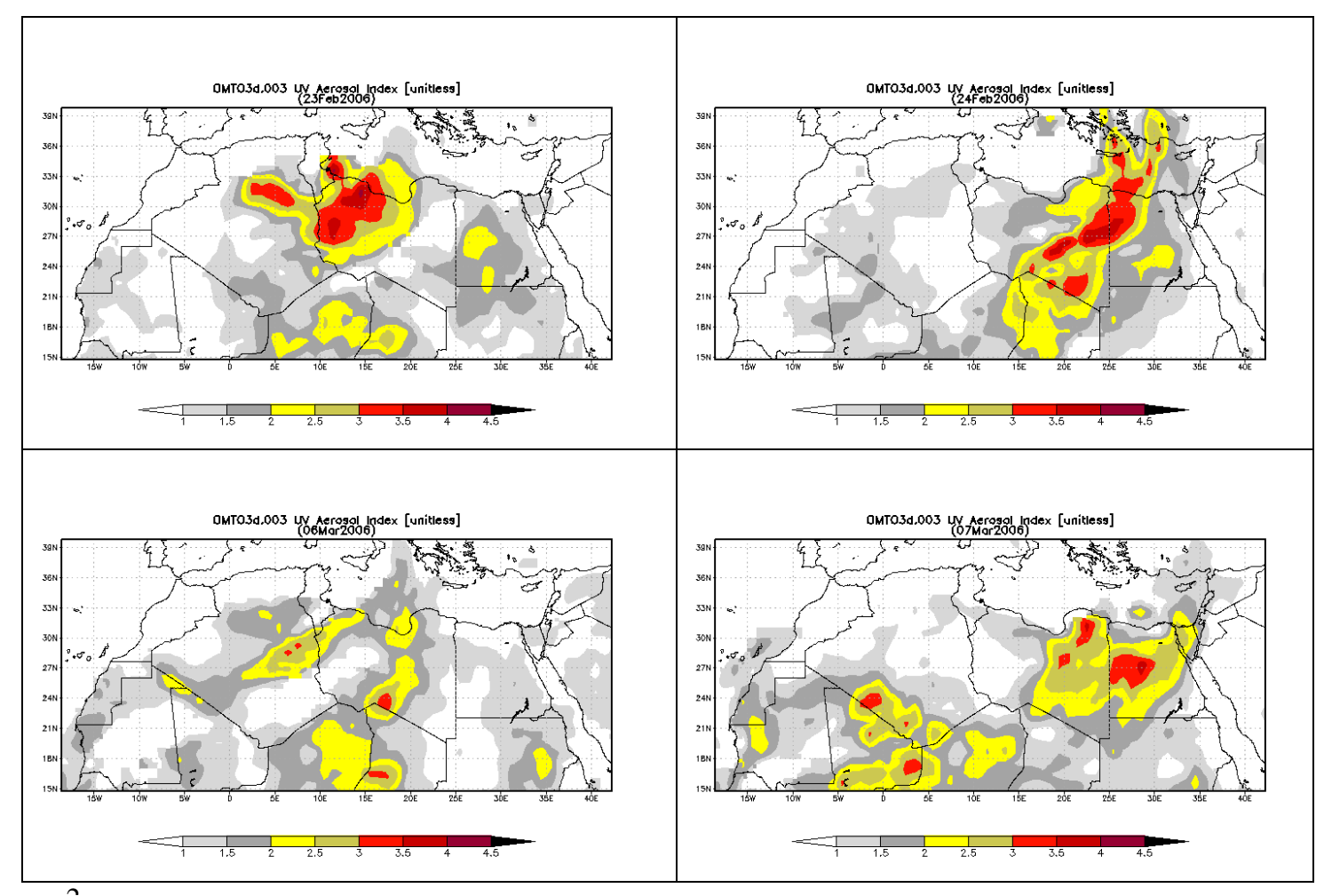

Fig. 7. Daily aerosol UV indexes derived from OMI satellite observations for 23 and 24 February 2006 (up) and for 6 and 7 March 2009 (down). 


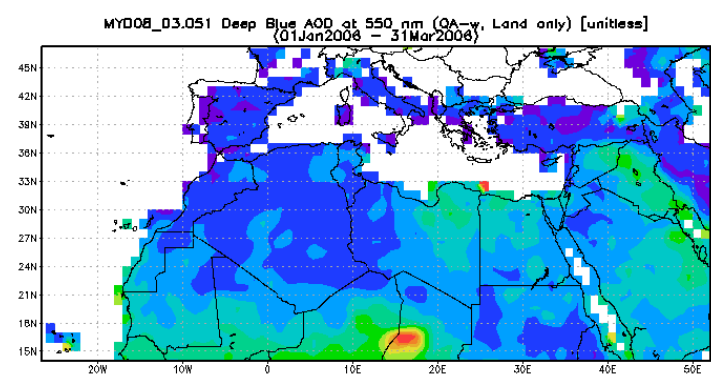

(a)
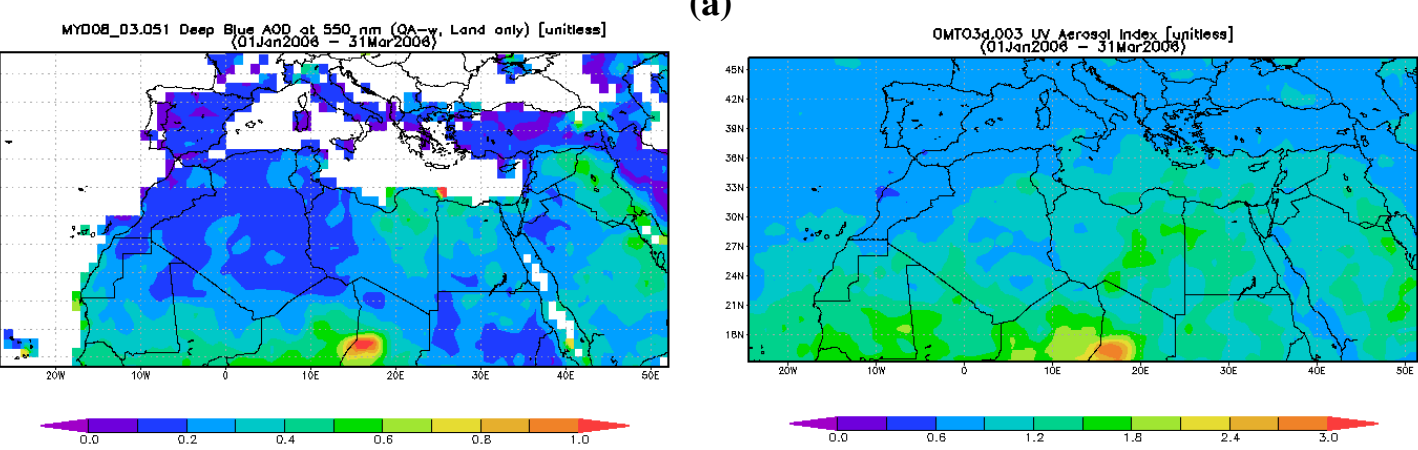

(b)
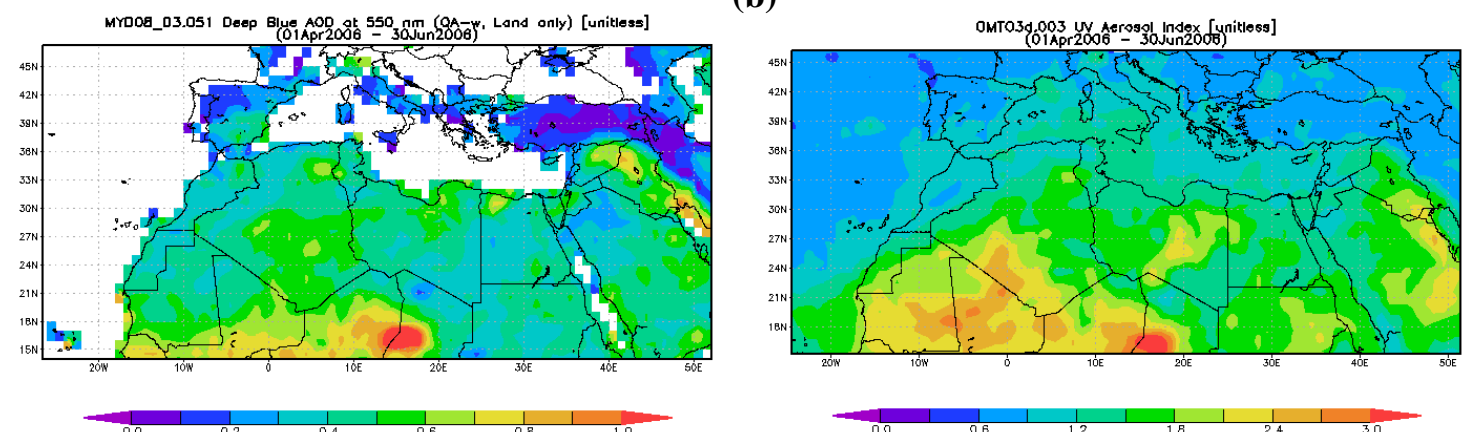

(c)
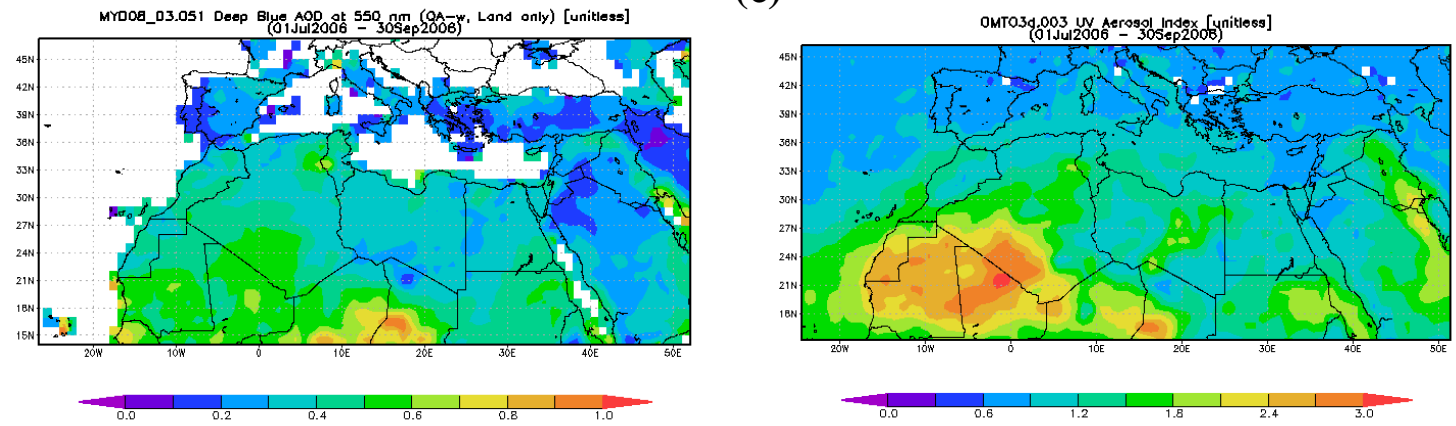

(d)
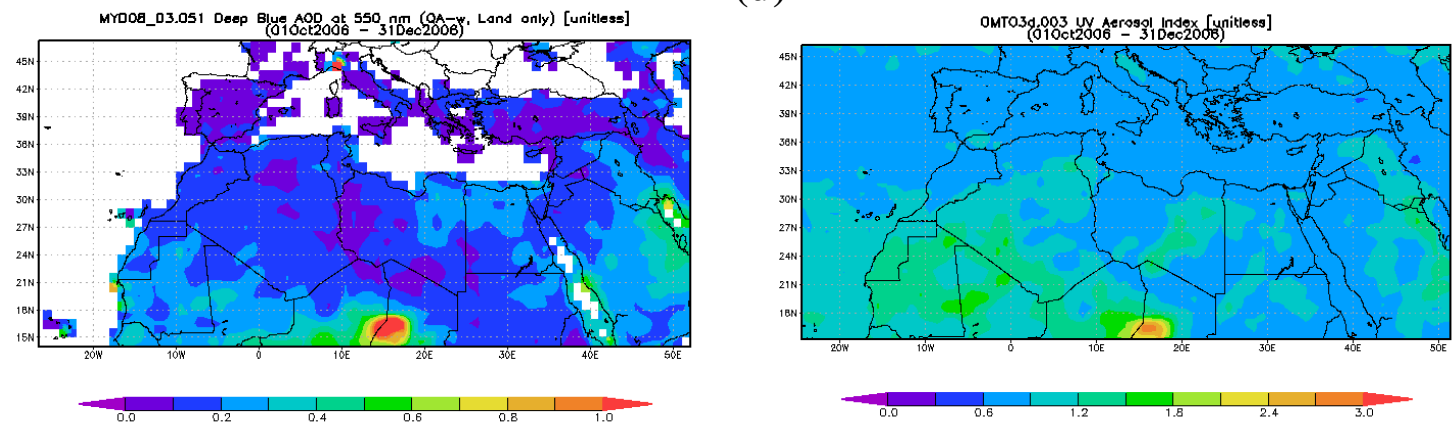

Fig. 8. Seasonal mean MODIS Deep Blue AOD (left) and OMI Aerosol Index (right) for (a) January-February-March 2006, (b) April-MayJune 2006, (c) July-August-September and (d) October-November-December 2006. 
dust source. Such a spatial pattern perfectly matches with satellite observations and in particular with Deep Blue AOD (Fig. 8d).

This seasonal displacement of the Saharan dust sources was already pointed out by Brook et Legrand (2000), who examined the seasonal distribution of the major dust sources based on a climatology (1984-1993) of Infrared Difference Dust Index (IDDI) derived from the Meteosat IR-channel (Legrand et al., 1994). From this climatology, the most active sources in January-February-march are the East SahelSahara, the North-central Sahara and the Northern Niger regions. A broad shift of the dust sources, from East of $5^{\circ} \mathrm{E}$ to West of $15^{\circ} \mathrm{E}$, was observed in April-March-May. In JuneJuly-August, the highest IDDI were confined to west of $5^{\circ} \mathrm{E}$ and between $17^{\circ} \mathrm{N}$ to $25^{\circ} \mathrm{N}$. The period October-NovemberDecember was characterized by the lowest IDDI values, except in the region of the Bodélé Depression, in the North of Niger and south of the Western Great Sand Sea $\left(\sim 0^{\circ} \mathrm{E}-\right.$ $25^{\circ} \mathrm{N}-30^{\circ} \mathrm{N}$ ).

The simulated seasonal distribution of the dust sources is thus very consistent with the distribution derived from three independent aerosol satellite products.

\subsection{Dust content over the Sahel}

\subsubsection{Monthly time scale}

To test the capability of the model to quantitatively retrieve the seasonal variations of the mineral dust content in the Sahelian region, the simulated monthly AODs and surface concentrations have been compared to the measurements from the SDT stations.

The order of magnitude of simulated monthly mean AOD are in good agreement with the measurements at the three stations (Fig. 9), especially between February and June. In Banizoumbou, the maximum measured AODs recorded in March $(0.97)$ and in June $(\sim 0.90)$ are well reproduced by the model (respectively 1.2 and 0.97 ). Slightly lower maxima are measured in Cinzana, with a higher monthly AOD in June (0.82) than in March (0.7) that are also retrieved in the simulations (0.65 in March and 0.89 in June). In M'Bour the March maximum (0.69) is well simulated (0.69) while in June the monthly AOD (0.67) is overestimated in the simulation (1.00). The lowest monthly AODs are recorded between July and October in Banizoumbou and Cinzana and later in the year (November to February in M'Bour. The simulated summer AODs tend to be significantly underestimated in Banizoumbou and Cinzana but correctly retrieved in M'Bour. In January, there is a clear underestimation of the AODs at the three stations. On the opposite, the AODs simulated in November and December are strongly overestimated in Banizoumbou and a little less in Cinzana.

The simulated monthly AODs are significantly correlated with the measured ones regarding the number of data used for the regression (Table 1) (Fig. 10). The slope of the linear
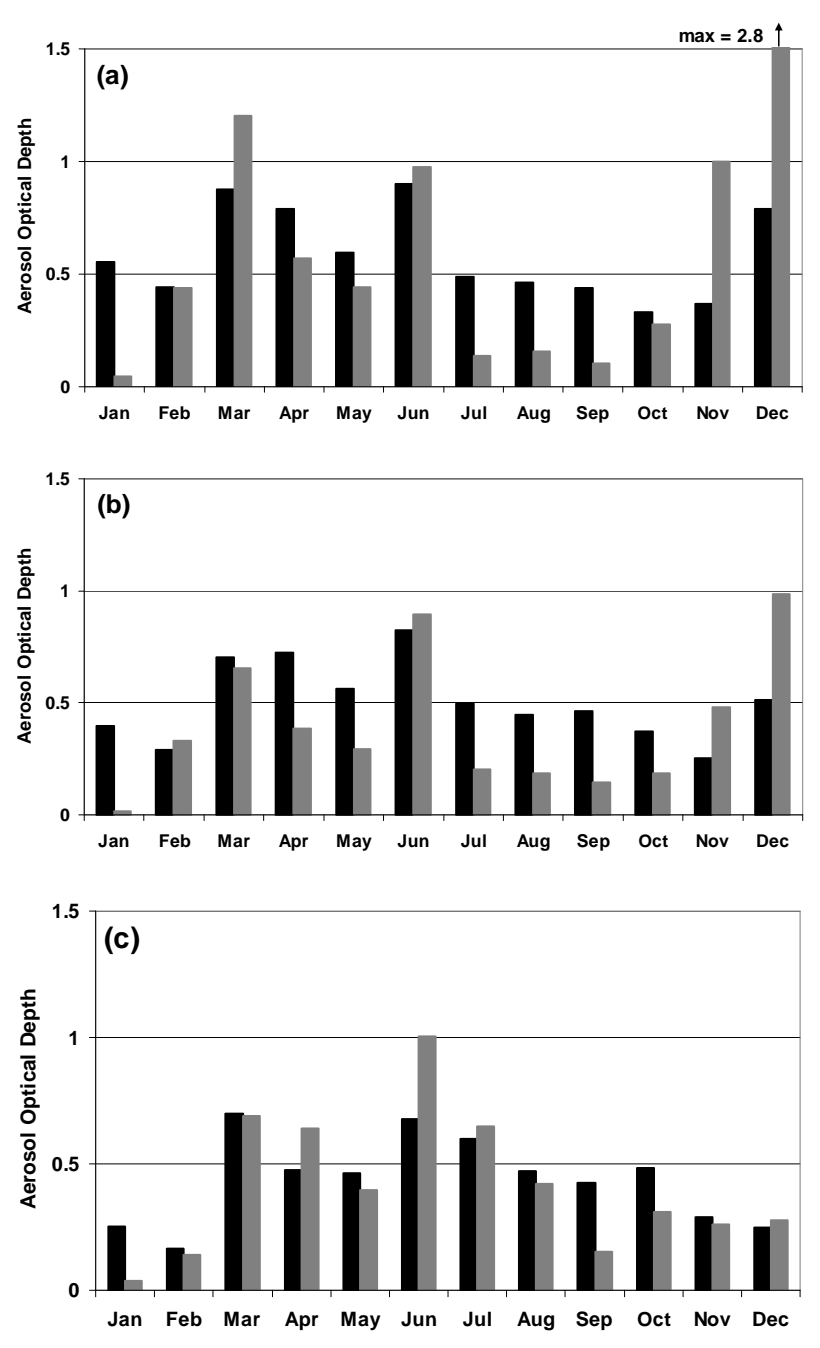

Fig. 9. Monthly mean aerosol optical depths measured by the AERONET sunphotometers $(675 \mathrm{~nm}$; level2) for $\alpha<0.4$ (black) and monthly mean coinciding simulated AOD $(550 \mathrm{~nm})$ (grey) for (a) Banizoumbou (Niger), (b) Cinzana (Mali) and (c) M'Bour (Senegal) in 2006.

regression indicates that the model tends to overestimate the measured monthly AODs, but the intercept tends to compensate this overestimation. Both the fractional and the normalized mean errors are of the order $50 \%$, with a relatively low normalized bias $(7 \%)$ but a quite high and negative fractional bias $(-31 \%)$. When excluding the abnormally low values of January at the three stations and the abnormally high values of November and December in Banizoumbou, the parameters of the linear regression are significantly improved and the errors and biases decreases (Table 1).

The level of agreement between the simulated and measured surface concentrations is not expected to be as high as for AODs. The first reason is that the simulated "surface" concentration corresponds to an average concentration in a well-mixed layer of $54 \mathrm{~m}$ height while surface $\mathrm{PM}_{10}$ 


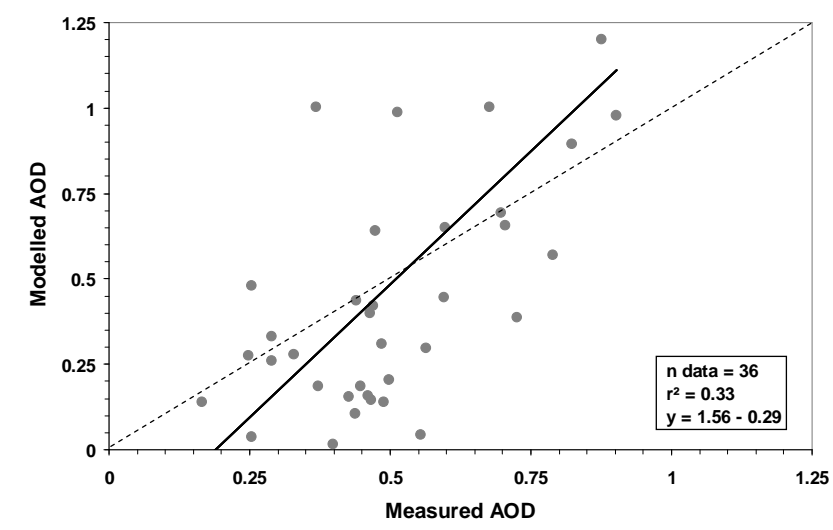

Fig. 10. Monthly mean simulated and measured AOD at the three station of the Sahelian Dust Transect in 2006. (the dotted line shows the $1: 1$ line and the continuous line correspond to the best fit of a linear regression, see parameters of the regression in Table 1).

measurements are concentrations measured close to the surface $(\sim 6 \mathrm{~m})$. A second reason is that the range of variation of the measured $\mathrm{PM}_{10}$ concentrations is much larger (16 to $\left.388 \mu^{-3} \mathrm{~m}^{-3}\right)$ than for the measured AODs (0.16 to 0.9), i.e. a ratio of maximum to minimum monthly means of about 24 for the concentrations and 5.4 for the AOD. Simulating correctly such a range of variation is thus very challenging. Marticorena et al. (2010) show that surface concentrations measured along the SDT are strongly impacted by local convective events at the beginning of the wet season, while median concentration are almost insensitive to the influence of these short duration events (10-30 min). To minimize the influence of these extreme local events, the median was chosen to compare modelled to measured concentrations (Fig. 11).

As expected, the simulated monthly surface concentrations are much lower than the measured ones in Banizoumbou and Cinzana. Nevertheless, the temporal pattern of simulated concentrations is very similar to the observations, with a first period of high concentrations between February and April and second period in November and December. During the summer, the surface concentrations are less underestimated than the AODs in Banizoumbou and Cinzana. On the opposite, the surface concentrations are strongly underestimated in January, which is consistent with the large underestimation of the AODs. The strong overestimation of the AODs in November and December is associated with strongly overestimated surface concentrations only at the station of Banizoumbou, while in Cinzana the simulated concentration are in the same order of magnitude than the measured ones.

Surprisingly, the simulated concentrations are higher than the measured concentrations in M'Bour. In addition, in M'Bour the two monthly maxima (March and May appear) as slightly shifted in the simulation (April and June) compared to the observations. Since the simulated AODs fit well
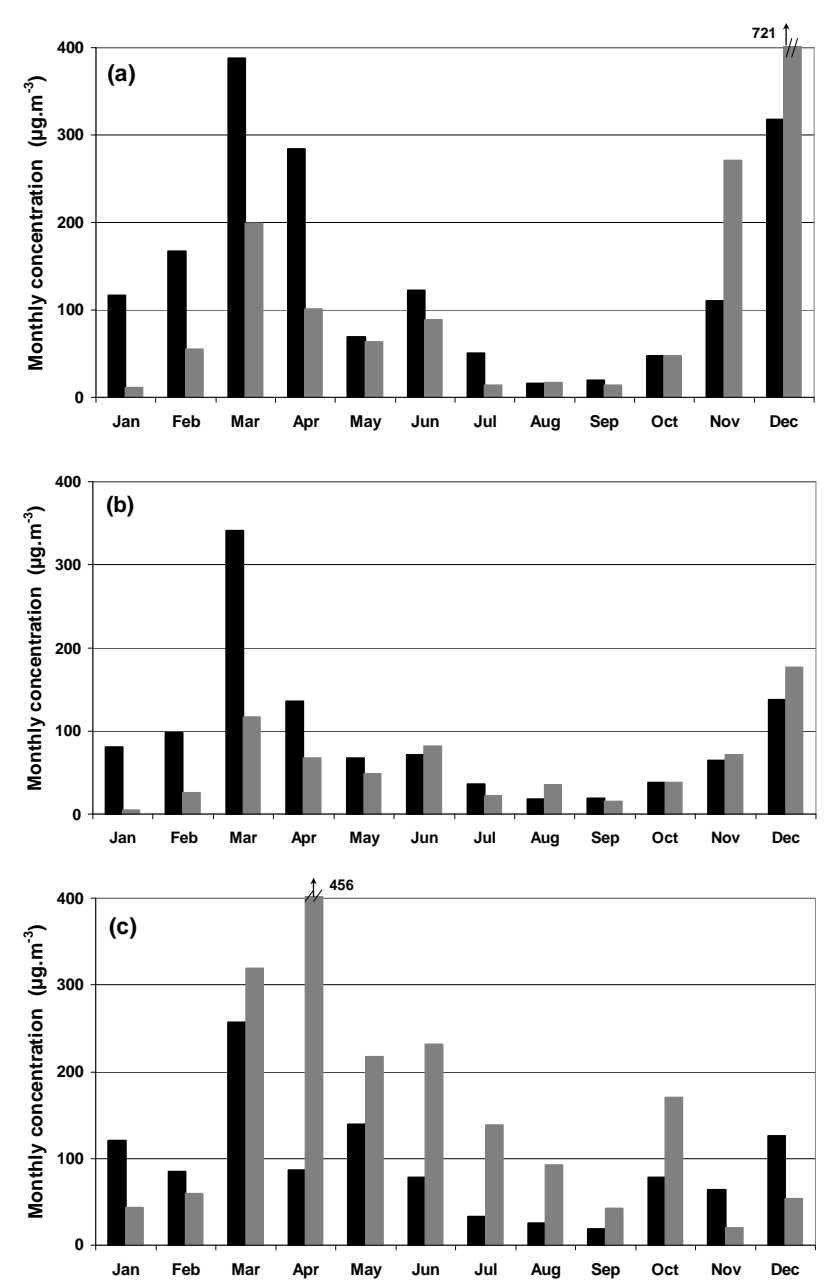

Fig. 11. Monthly mean of daily median measured (black) and simulated (grey) surface concentrations in (a) Banizoumbou (Niger), (b) Cinzana (Mali) and (c) M'Bour (Senegal).

the measured AODs, this suggests a bias in the vertical distribution of the transported dust.

At the three stations, the temporal pattern and the timing of the monthly maximum of surface concentrations are in good agreement with the measurements. The simulated monthly median concentrations are significantly correlated to the measured ones ( $R=0.51$ with $n=36$ ). The fractional mean error and the normalized mean error are of the order of $70 \%$ (respectively 68 and $75 \%$ ), i.e. as expected much higher than for the AODs. However, the fractional and normalized biases are much lower (-14\% and $6 \%)$ than for the AODs, which can result from compensations between negative and positive biases. The level of agreement between the simulated and observed monthly concentrations is thus comparable to the model criteria recommended by Boylan and Russel (2006).

These comparisons show that the model satisfyingly reproduces the order of magnitude of the monthly mean AODs 
and median surface concentrations between February and October. The simulated temporal pattern of AODs and concentrations are very similar to the observed ones during this period. The simulated AODs and surface concentrations are strongly underestimated in January. This underestimation cannot be simply attributed to underestimated dust emissions. Indeed, the simulated dust emissions in January (104 Mt) are comparable to those simulated for August (118 Mt) and about twice higher than in November (57 Mt). But the AODs simulated in the three Sahelian stations are about one order of magnitude lower than the observations in January, while they are relatively consistent with the measurements in August in Cinzana and M'Bour, and largely overestimated in Banizoumbou and Cinzana in November. The explanation of these discrepancies can be related to the dust source location. The most intense sources simulated in January are located in the Central North-East Sahara (West and North of Libya) so the emitted dust is not transported to the Sahel. The monthly mean deep blue AODs and AI OMI confirmed the occurrence of dust emissions over the North of Libya but not in western Libya and point out the Bodélé Depression as the most intense dust source at this period. In the simulations, no dust emissions are simuated in the region of the Bodélé Depression in January, meaning that the surface winds are below the erosion threshold and the correction on the wind fields is not activated. On the opposite, in November and December the simulated dust emissions are localised in the Bodélé depression only and thus efficiently transported to the stations of Banizoumbou and Cinzana. Since both the AODs and the surface concentrations are overestimated, it can be concluded that the simulated dust emissions from this area are too intense and thus the corrected surface winds too high. These two opposite results on the emissions from the Bodélé Depression suggest that the correction on the surface winds, established for data measured in the spring, may not be totally appropriate all along the year, but should be modulate as a function of time depending on the meteorological conditions.

The underestimation of the AODs and surface concentration in the summer in Banizoumbou and Cinzana could be explained by an overestimation of the wet deposition. This hypothesis is reinforced by the fact that in M'Bour, which is located in a region with less precipitations than the two other stations, the summer AOD and concentrations are overestimated compared to the measured ones. The fact that in M'Bour the surface concentrations are much more overestimated than the AODs may also reflect a bias in the simulated vertical distribution.

At the monthly scale, the level of agreement between the simulations and the observations quantified by the statistical indicators (Table 1) is comparable to the recommendation for $\mathrm{PM}_{2.5}$ model evaluation goal and much lower than the range reported for $\mathrm{PM}_{10}$ simulations in air quality models (Boylan and Russel, 2006).

\subsubsection{Daily scale}

Comparison between simulations and observations at a daily scale allows us to evaluate the capability of the model to reproduce the intensity and the frequency of the single dust events contributing to the monthly mean atmospheric dust load.

The AOD simulated with CHIMERE-DUST with a one hour time step have been compared to the hourly measured AOD at the three stations of the SDT (Fig. 12).

Consistently with the seasonal cycle of the monthly mean AOD, the highest peaks in AOD are observed in winter and spring in Banizoumbou and Cinzana, but later in the summer in M'Bour. These intense dust events leads to AOD generally higher than 0.5 and can reach AOD up higher than 3 at their maximum. The measured AOD tends to be higher in Banizoumbou than in Cinzana, and higher in Cinzana than in M'Bour. At the three stations, the major observed peaks in AOD are well reproduced by the model in terms of timing and intensity. On the opposite in November and December moderated dust events recorded in Banizoumbou and Cinzana are strongly overestimated by the model. The maximum AODs measured during these events in Banizoumbou and Cinzana range between 0.6 and 0.7 in November and 1.6 to 1.8 in December while the simulated AOD for the same events ranges between 1.6 and 3 in November and are as high as 7.9 in Banizoumbou and 3.8 in Cinzana in December. The major simulated dust source during this season is the region of the Bodélé Depression. The overestimation of the AODs in November and December confirms that the correction of the surface wind in this region is too strong at this period as already suggested above. Nevertheless, since the timing of the dust events is correctly retrieved, this tends to confirm that the erosion threshold that controls the dust events frequency is reasonably well estimated. In Banizoumbou and Cinzana, the maximum monthly mean at the end of winter is explained by a very large peak corresponding to the March 2006 dust storm ( Julian day 60$)$. During this dust event, the simulated AOD reaches a maximum of 4 in Banizoumbou in agreement with observations. In Cinzana the maximum AOD $(\sim 2)$ is slightly underestimated compared to the measurements $(\sim 3)$. The simulation of this specific event will be further detailed in Sect. 3.3.1. During spring, several peaks, less intense, occur and for which the AOD are well captured by the model in Banizoumbou (between 1 and 2 ) and in Cinzana $(\sim 1)$ with the correct timing, for example on 31 March and 20 April in Banizoumbou and Cinzana and on 20 May in Banizoumbou. At this season, the gradient in AOD observed from Banizoumbou to Cinzana, mainly due to the dilution of the dust plume during its transport, is well reproduced by the model. The spring period ends with a relatively long dust transport event ( $\sim 10$ days $)$ at the beginning of June, remarkably well reproduced by the model in the three stations in terms of magnitude and duration, as further described in Sect. 3.3.2. 

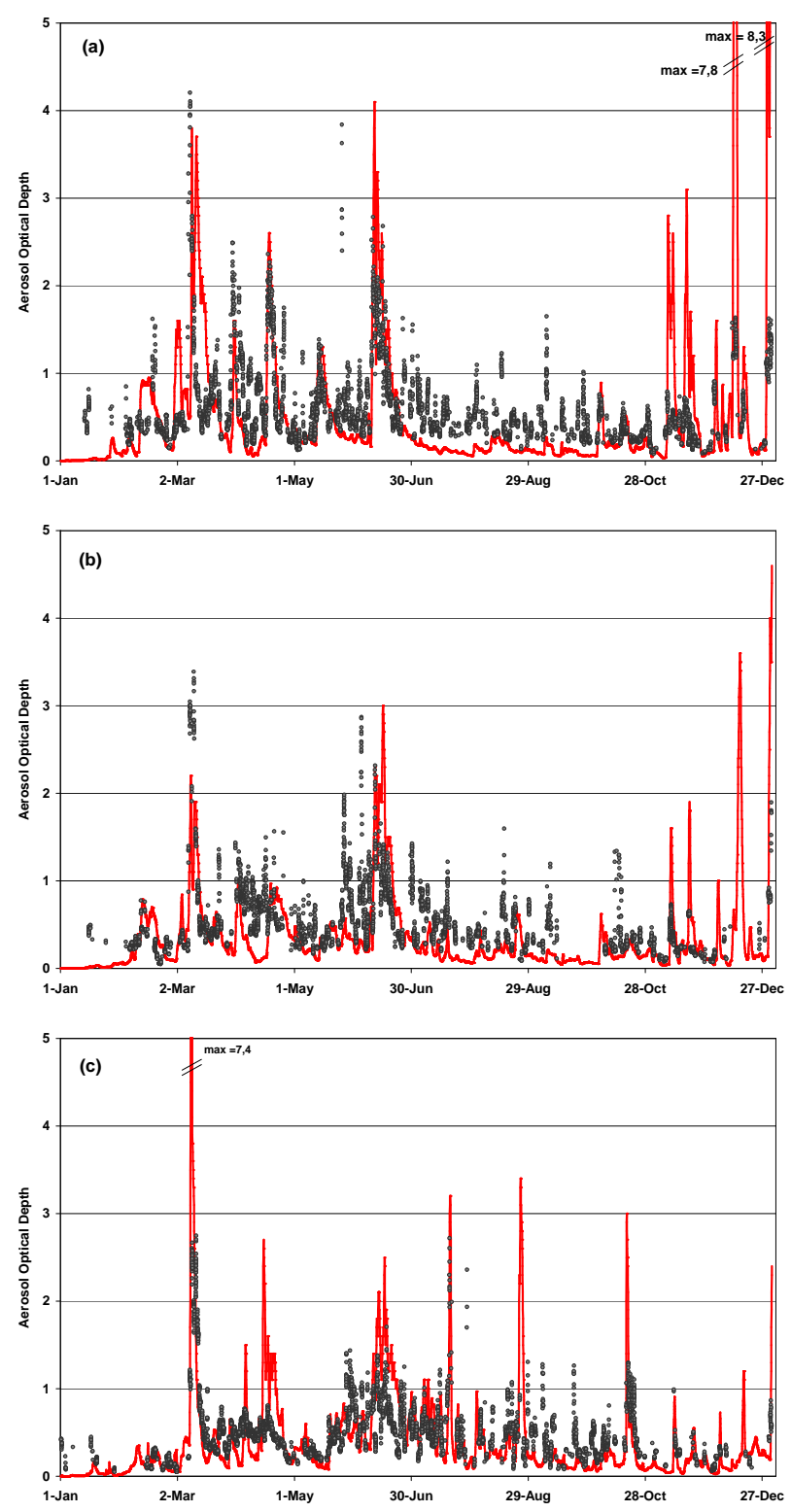

Fig. 12. Measured aerosol optical depth (level 2 data @675 nm at nominal time resolution) with $\alpha<0.4$ (grey circles) and hourly simulated aerosol optical depth (@550 nm) (red line) in (a) Banizoumbou (Niger), (b) Cinzana (Mali) and (c) M'Bour (Senegal) in 2006.

In M'Bour, except in March, the measured AODs associated with mineral dust are lower than in the two other stations. In the spring, the measured AODs tend to be overestimated by the model. The highest AOD is measured during the March dust storm. The timing of this event is well captured by the model. However, the maximum simulated AOD is 7.4, while the measured AOD is $\sim 3$. However, the simulated maximum AOD is lower than in the regional simulations by Schepanski et al. (2009) or Menut et al. (2009) for the same event. Two dust events of low intensity $(\mathrm{AOD}<1)$ are also measured before and after 10 April, but the corresponding simulated AOD are overestimated by a factor 2 .

During summer, high AODs are recorded in Banizoumbou and Cinzana but the duration of the events is shorter than during spring. Only a few of these events are recorded in M'Bour. This may correspond to local dust emissions and transport by meso-scale convective systems, as described by Marticorena et al. (2010). Such meteorological systems are not correctly simulated by global meteorological models. So the ECMWF meteorological forcing used for the simulation does not allow to reproduce the impact of these systems on the dust concentrations.

Several dust events occur between June and September in M'Bour, when dust sources located close to the North of the Senegal, in Mauritania and in Western Sahara are activated (Fig. 8b and c). The timing of these events is well reproduced or only slightly in advance compared to measurements. For these events, the simulated AOD are in agreement with the measured ones. Finally, in December, the AODs associated to the dust events are not overestimated by the model in M'Bour compared to Banizoumbou and Cinzana.

In January, the simulated AODs are much lower than the measured one, however, it must be noted that only few measurements have been retained for the comparison during this period mainly due to the selection of AODs with $\alpha$ lower than 0.4 , i.e. non ambiguously attributed to dominant mineral dust conditions.

The correlation between the simulated hourly AODs and the measured ones increases as a function of the distance to the main dust sources, i.e. from Banizoumbou $(r=0.44)$ to M'Bour $(r=0.65)$. The slope of the linear regression is close to 1 in Banizoumbou (0.99), much lower in Cinzana (0.60) and even lower in M'Bour (0.39). On the other hand, the NMEs vary from $74 \%$ in Cinzana, $82 \%$ in Banizoumbou and $91 \%$ in M'Bour, while the MFEs are comparable at the three stations (from 73 to $75 \%$ ). Like for the monthly AODs, the NMB are still low (-14\% to $12 \%)$ but the MFEs are negative at the three stations $(-31 \%$ to $-41 \%)$ confirming an underestimation trend in the model. The level of agreement between the simulated and observed AODs is thus lower at the hourly scale than at the monthly scale. The fractional error and bias are too high to meet the PM model evaluation goals defined by Boylan and Russel (2006), but still in the range defined as model evaluation criteria.

The daily median concentrations in the first layer of the model are superimposed to the daily median surface concentrations measured at the three stations on Fig. 13. At the daily time-scale, a logarithmic scale is used because the measured daily concentrations span over more than 3 orders of magnitude (from less than $1 \mu \mathrm{g} \mathrm{m}^{-3}$ to $4200 \mu \mathrm{g} \mathrm{m}^{-3}$ ). The simulated surface concentrations exhibit the same order of magnitude than the measured ones (from about $5 \mu \mathrm{g} \mathrm{m}^{-3}$ to $1700 \mu \mathrm{g} \mathrm{m}^{-3}$ ). In particular the maximum simulated surface concentrations are as high as the measured ones, i.e. from 

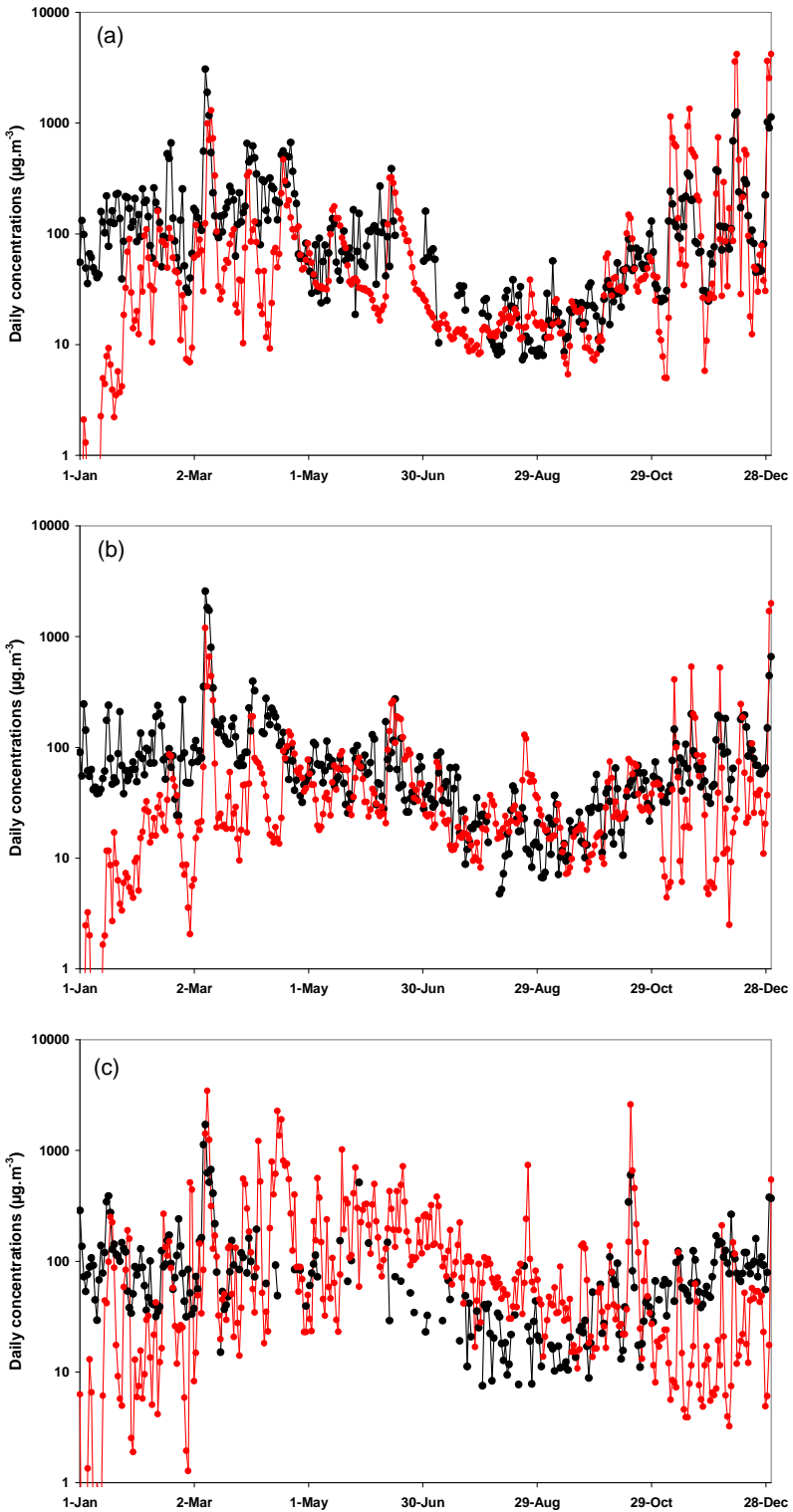

Fig. 13. Daily median measured (black dots) and simulated (red dots) $\mathrm{PM}_{10}$ surface concentrations in (a) Banizoumbou (Niger), (b) Cinzana (Mali) and (c) M'Bour (Senegal) in 2006.

1000 to $4000 \mu \mathrm{g} \mathrm{m}^{-3}$ in Banizoumbou. While the order of magnitude of the peaks is well reproduced, background concentrations are much lower for the simulations than for the measurements. Like for the AOD, the temporal variability of the dust concentrations at the annual scale is realistically simulated at the three stations, except in January when the model simulates extremely low concentrations (lower than $10 \mu \mathrm{g} \mathrm{m}^{-3}$ ). The maximum concentrations recorded during the March dust storm are reasonably well reproduced in terms of timing. From June to September, the modelled concentrations are in the same range than the measured daily median concentrations, indicating that, except for convective situations, the model correctly reproduces the observed decrease of the concentrations during the rainy season. During the dust events recorded in December, the simulated concentrations exhibit a large variability, with an overestimation of the maximum concentrations, especially in Banizoumbou, but also a strong underestimation of the lower concentrations recorded between the dust events, especially in M'Bour. However, the overestimation of the concentrations is not as high as the overestimation of the AOD. As already noted at the monthly scale, the summer concentrations simulated in M'Bour are clearly overestimated compared to the measurements.

The correlation coefficients between the simulated and measured daily median concentrations are lower than for the AOD, but do not exhibit any spatial trend. The correlation coefficient, $r$, is higher in Cinzana (0.58) than in Banzoumbou (0.55) and M'Bour (0.45). The Normalized Mean Errors ranges from $75 \%$ in Cinzana to $121 \%$ in M'Bour, with an intermediate value of $96 \%$ in Banizoumbou. The fractional mean errors are of the same order of magnitude, but the variability between the three station is lower ( 82 to $104 \%$ ). The normalised bias are also quite high, with the largest and negative bias in Cinzana $(-36 \%)$ and a positive bias in M'Bour $(28 \%)$. The mean fractional biases are clearly negative at the three stations (from $-27 \%$ to $-53 \%$ ). All the statistical parameters show a lower level of agreement between the simulations and the observations for the daily concentrations than for the monthly concentration. They are also lower than those obtained for the AODs, even at the hourly scale. This can be explained by the much large range of recorded and simulated concentrations ( $\sim 3$ orders of magnitude). According to these numbers, the simulation does not meet the model evaluation criteria for $\mathrm{PM}_{2.5}$ from Boylan and Russel (2007). However, they are consistent with the range reported for $\mathrm{PM}_{10}$ simulations with comparable MFE but lower MFB and lower than those reported for "soil" dust simulations in air quality models. This suggests that our dust model reproduce the observed dust concentration with reliability comparable to the reliability of air quality models for $\mathrm{PM}_{10}$.

\subsection{Typical dust events}

To further investigate the model performances, we then focus on two typical events observed in March and June 2006 in Banizoumbou for which quantitative information on the altitude of the dust layers is available.

\subsubsection{A typical low layer transport case: the March 2006 dust storm}

In March 2006, a continental dust storm affects the whole Sahara and West Africa. This dust storm was initiated by a cold front in the south of the Atlas that progressed southward and westward, producing dust all along its path (Slingo et al., 2006). It produces extremely intense dust concentrations 
observed between 8 March and 10 March in the three stations of the Sahelian dust transect (Marticorena et al., 2010).

Once again, both the AOD and surface concentrations measured along the SDT have been compared to the simulations from 1 March to the 31 March.

The AODs (Fig. 14) and the concentrations (Fig. 15) measured during this event exhibit a similar temporal pattern, suggesting that most of the dust transport occurs in a well mixed low layer. In Banizoumbou, the more severe dust conditions (concentrations higher than $1000 \mu \mathrm{g} \mathrm{m}^{-3}$ ) are recorded between 7 and $10 \mathrm{March}$, with a sharp increase of the concentration and of the AOD in the morning of 7 March and two successive sharp peaks on the 8th and 9th and a larger one on the 10th. The simulated concentrations exhibit a first but moderate increase on the 8th and two major increases on 9 and 11 March. The first increase is much lower than the observed one and it is not associated with a peak in the AOD. The simulated maximum AODs (3.8 and 3.7) are close to the maximum measured AODs (4.2) but they remains higher than 1 for a longer period than the observed AODs. On the opposite, the maximum simulated surface concentrations (1386 and $1500 \mu \mathrm{g} \mathrm{m}^{-3}$ ) are lower than the measured maximum (from 2747 up to $4800 \mu \mathrm{g} \mathrm{m}^{-3}$ ). After 11 March, the simulated AODs are overestimated compared to the observed one, while the surface concentrations are of the same order of magnitude than the measured ones. Compared to the observations, the simulated dust event is delayed of about $20 \mathrm{~h}$. Despite this shift, the temporal variations of the surface concentrations are remarkably well reproduced by the model, not only for this event but for the whole month. This delay in the maximum of AOD and concentration and their underestimations suggest that the dust mobilization occurs too late in the simulations and may not be sufficiently intense. A comparable delay was obtained by Stanelle at al. (2010) who simulated the same dust event with the COSMO-ART model forced by the analyses of the Integrated Forecast Systems from ECMWF; i.e. similar meteorological fields than the one used in this work.

One day later than in Banizoumbou, the dust event reaches the station of Cinzana, producing maximum AODs of 3 and 3.4 and surface concentrations as high as 3250 and $2900 \mathrm{\mu g} \mathrm{m}^{-3}$ (Figs. 14b and 15b). Both the simulated maximum AODs and concentration are slightly lower than the observations (2.2 and 1.9 for the AOD and 1400 and $690 \mu \mathrm{g} \mathrm{m}^{-3}$ for the surface concentrations). In this case, the first simulated peak is delayed of $4 \mathrm{~h}$ only and the duration of the events is similar to the observed one. In M'Bour, the timing and duration of the dust events is well reproduced. The simulated AOD reaches a maximum of 7.4 (Fig. 14c), while the available measurements do not exceed 2.6. But the simulated AODs coinciding with available measurements are in reasonable agreement with the observations. M'Bour is the only station where the simulated concentrations are higher than the observations (Fig. 15c).
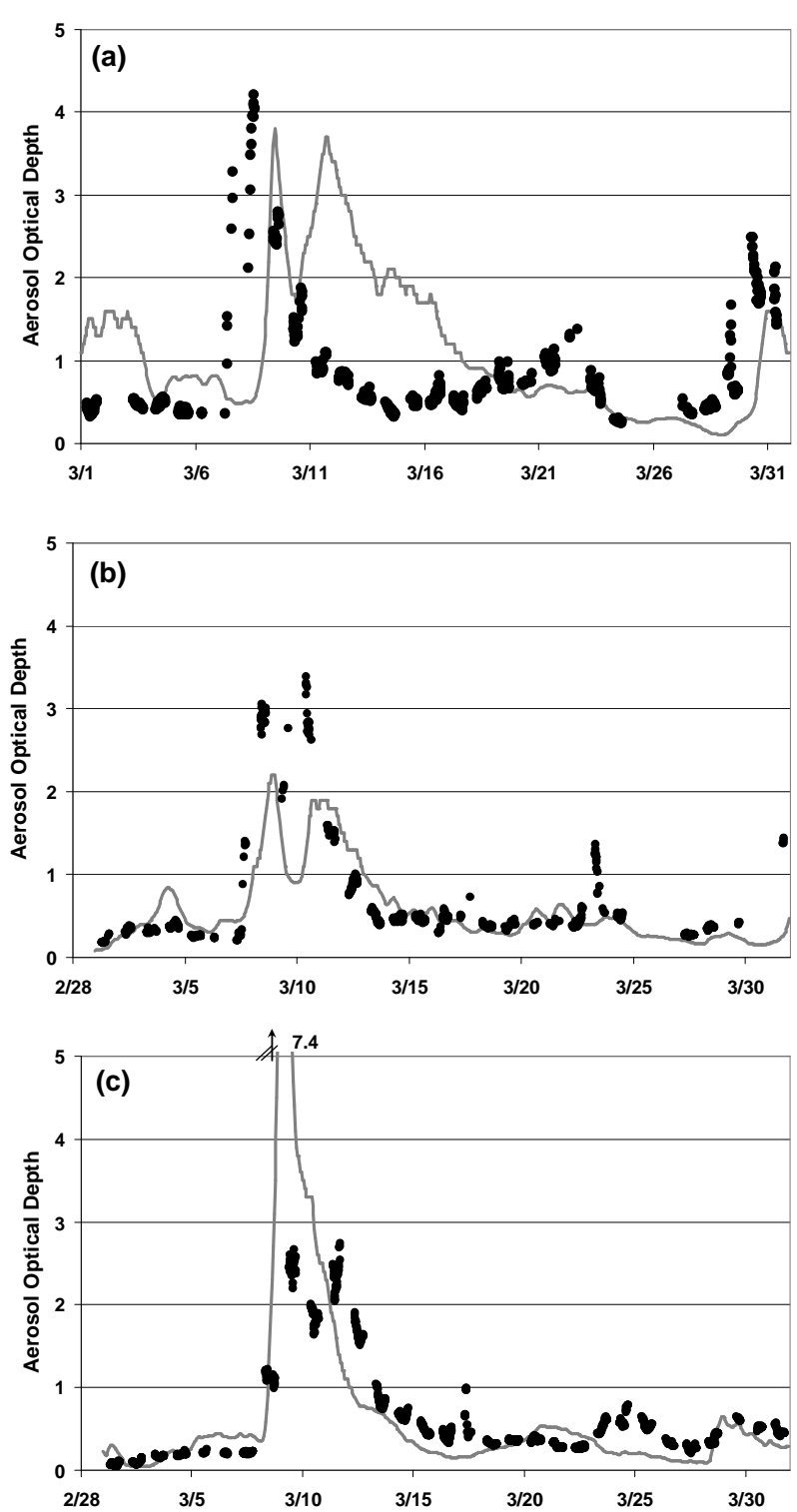

Fig. 14. Measured (black dots: AERONET level 2 data @675 nm) and simulated (grey line) hourly Aerosol Optical Depth (@550 nm) over (a) Banizoumbou (Niger), (b) Cinzana (Mali) and (c) M'Bour (Senegal) in March 2006.

During this event, several dust clouds are successively activated and spread over the Sahara, progressing southward, to finally produce a huge continental dust cloud. The examination of SEVIRI (Spinning Enhanced Visible and Infrared Imager) special dust products from EUMETSAT (European Organisation for the Exploitation of Meteorological Satellites) shows the activation of different dust sources affecting the different stations (Marticorena et al., 2010). On 7 March 2006, the station of Banizoumbou is overpassed by a North-eastern dust plume, while another dust plume is located North-West of the station of Cinzana. A dust cloud is 

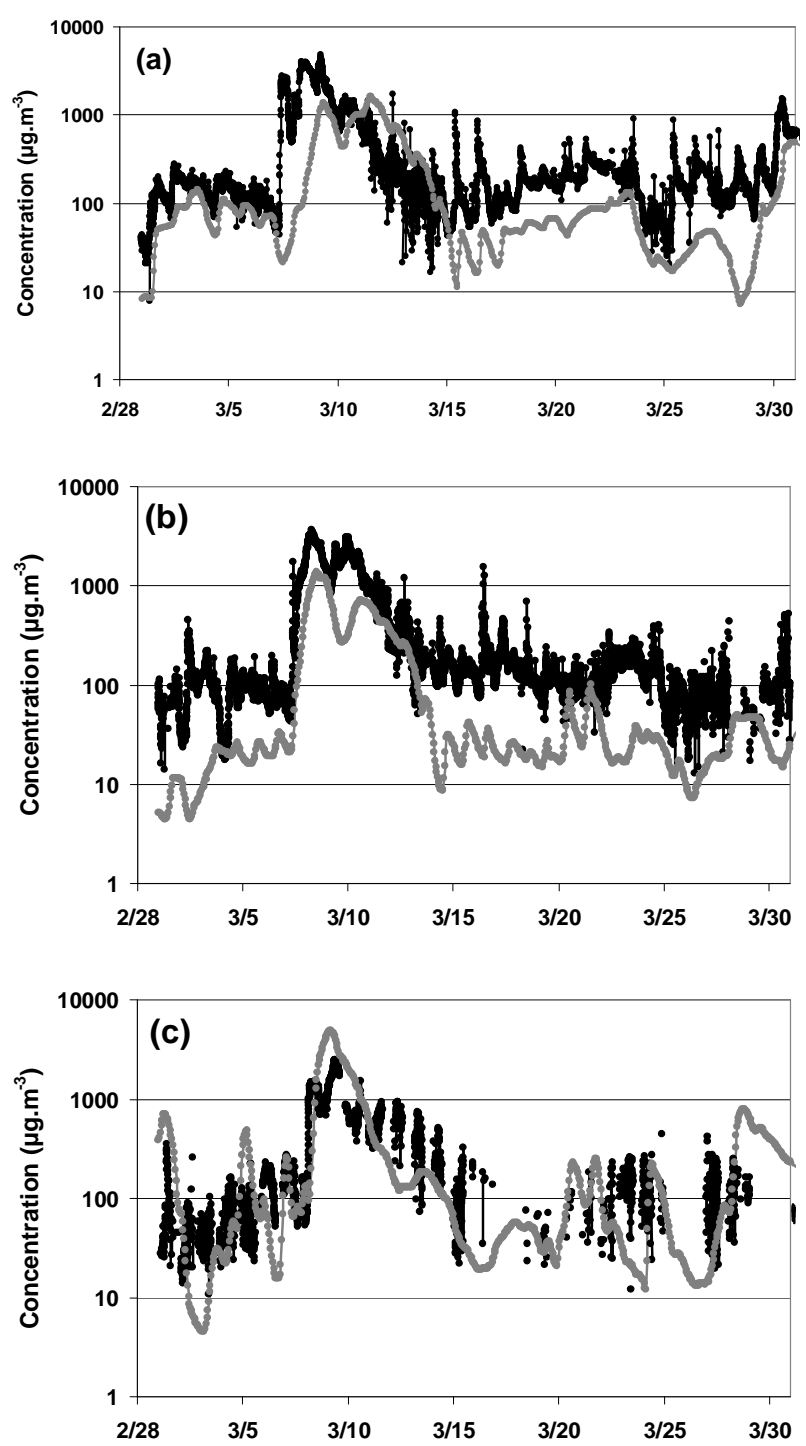

Fig. 15. Measured (black dots) and simulated daily $\mathrm{PM}_{10}$ surface concentrations in (a) Banizoumbou (Niger), (b) Cinzana (Mali) and (c) M'Bour (Senegal) in March 2006.

also visible North-East of M'Bour that progressively moved south-westward. These differences in the source locations and emission timing explain the different levels of agreement between the simulations and the observations at the three stations.

This event has been simulated by several authors using mesoscale meteorological models (Tulet et al., 2008; Schepanski et al., 2009; Stanelle et al., 2010) and with the CHIMERE-DUST model in forecast mode (Menut et al., 2009). The AOD measured in Banizoumbou is correctly reproduced with the meteorological model Meso-NH model coupled with the DEAD dust emission and deposition model (Tulet et al., 2008). On the opposite, they are strongly overestimated $(>10)$ in Banizoumbou and Cinzana

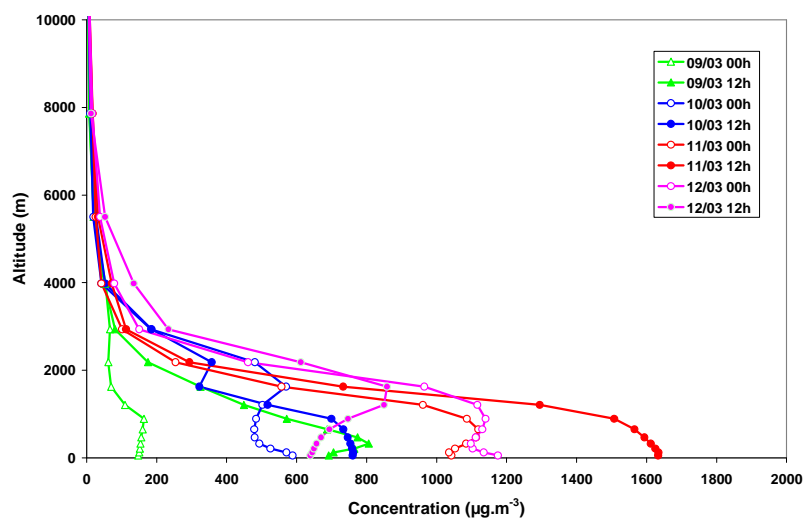

Fig. 16. Simulated vertical distributions of the dust concentration over Banizoumbou (Niger) during the March 2006 dust event.

( $>10$ ) using the dust transport model LM-MUSCAT (Schepanski et al., 2009). A similar overestimation is obtained with the CHIMERE-DUST model run in forecast mode using the MM5 model forced by the NCEP global meteorological fields (Menut et al., 2009). However, the surface concentrations with the CHIMERE-DUST model in forecast mode at the three stations (Menut et al., 2009) have the same order of magnitude than in this work.

Figure 16 reports the vertical distribution of the simulated dust concentrations from 9 to 12 March 2006. The first peak in AOD and surface concentrations is simulated on the 9 March at 12:00 h UTC. The vertical profile on 9 March at 12:00 h clearly shows the development of a heavily loaded dust layer between 0 and $2000 \mathrm{~m}$, with a maximum around $300 \mathrm{~m}$. From 9 to $11 \mathrm{March}$, the surface concentration increases to more than $1500 \mu \mathrm{g} \mathrm{m}^{-3}$ while the depth of the layer extends up to $2000 \mathrm{~m}$. After 11 March the dust concentration progressively decreases, in particular close to the surface. On 12 March at 12:00 h UTC, the maximum dust concentration is located around $1600 \mathrm{~m}$. The dust layer depth never exceeds $2000 \mathrm{~m}$ during this dust event, and the simulated maximum dust concentrations are always located below $1600 \mathrm{~m}$.

The analysis of the vertical profile of temperature and humidity derived from radio sounding for this event revealed a well-mixed layer extending from the surface up to $860 \mathrm{hPa}$ ( $\sim 1500 \mathrm{~m}$ in standard atmosphere (Slingo et al., 2008). The vertical profiles of the backscatter coefficient, measured by the lidar of the US Atmospheric Radiation Measurement (ARM) Mobile facility located in Niamey (Niger) in 2006, indicates an intense backscatter in this layer due to the presence of mineral dust (Slingo et al., 2008). These observations show that this dust event is a low layer transport whose altitude is correctly simulated by the model. 


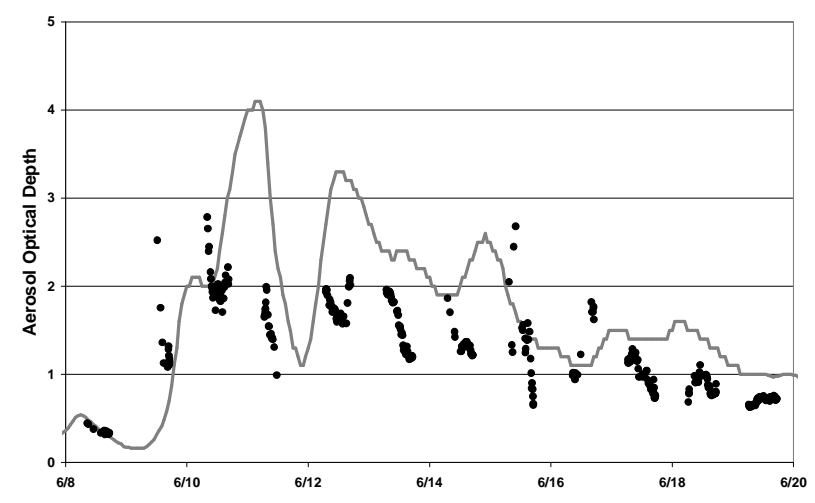

Fig. 17. Measured (AERONET level 2 data @675 nm) (black dots) and simulated hourly (@550 nm) (grey line) Aerosol Optical Depth over Banizoumbou (Niger) from 8 June 2006 to 20 June 2006.

\subsubsection{A high altitude transport layer case: 10-14 June 2006 Saharan dust transport}

During the period from 10 to 20 June 2006, AODs up to 2.5 are recorded over Banizoumbou (Fig. 17). This increase in the AOD corresponds to the arrival of a dust event originating from the Northern Sudan and Chad (Flamant et al., 2007). From satellite observations (OMI aerosol index; MODIS Deep Blue AOD), the largest aerosol loads are observed east of Niger on 9 June but the dust plume is progressively advected westward between 9 to 14 June (Flamant et al., 2007).

On 9 June, very low surface concentrations are recorded due to precipitations following the passage of a convective system (Fig. 18). Surface concentrations remain extremely low until the arrival of the Saharan dust event as indicated by the rapid increase of the AOD on June 10. The $\mathrm{PM}_{10}$ surface concentrations progressively increase from about $20 \mu \mathrm{g} \mathrm{m}^{-3}$ to reach $500 \mu \mathrm{g} \mathrm{m}^{-3}$ on 13 and 14 June. The measurements reported on Figs. 17 and 18, clearly show a decoupling in the temporal of the AODs and of the $\mathrm{PM}_{10}$ surface concentration, suggesting a high altitude transport.

During this event, the comparison between the simulated and measured AOD (Fig. 15) are in good agreement. From 8 to 10 June, the measured AOD raises from 0.3 to 2.8 in agreement with the simulated AOD (0.3 to 2.1). The simulated AOD are as high as 4 on 11 June but no AOD measurements are available for this day. From 12 to 16 June, the measured AOD range from 1.2 to 2.7 while the simulated AOD are between 2 and 3, i.e. slightly higher than the measured ones. However during the whole dust event, the temporal pattern of the simulated AOD is similar to the one depicted by the sunphotometer measurements. It can be noted that the maximum AODs are simulated during the night, when the sunphotometer cannot provide AOD measurements.

The measured $\mathrm{PM}_{10}$ surface concentrations during this period are also well simulated in terms of concentration range and in term of temporal variations (Fig. 18). The simulated

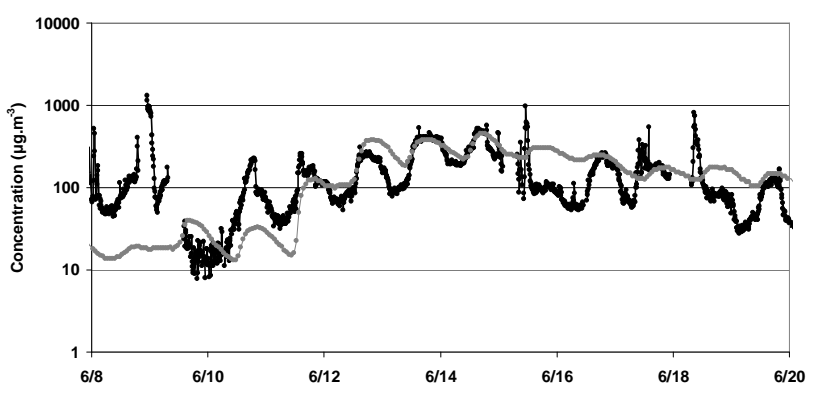

Fig. 18. Measured (black dots) and simulated (grey dots) $\mathrm{PM}_{10}$ dust surface concentrations in Banizoumbou (Niger) from 8 June 2006 to 20 June 2006.

dust concentrations reproduced the increase in concentration observed between 10 and 14 June with a correct magnitude and timing of the maximum concentration.

The evolution of the altitude of dust transport simulated in Banizoumbou from 9 to 15 June (at 12:00 h UTC), is illustrated in Fig. 19. A low concentration dust layer is initially simulated between 4 and $6 \mathrm{~km}$ height on 9 June. On 10 June, the maximum concentration is located at $5 \mathrm{~km}$, and the layer tends to extend downward. This also corresponds to the maximum simulated AOD. After 10 June, the dust layer peaks between 2 and $4 \mathrm{~km}$, with a maximum simulated concentration $\left(1200 \mu \mathrm{g} \mathrm{m}^{-3}\right)$ at about $3000 \mathrm{~m}$ on 12 June No lidar measurements from the ARM mobile facility have been published for this period. However, 13 June is the first day of 2006 for which vertical profiles from the CALIPSO (Cloud-Aerosol Lidar and Infrared Pathfinder Satellite Observations) spaceborne lidar are available. An aerosol layer located between 2 and 5 is clearly identified in the CALIPSO track over Africa at the latitude of Niamey (http://www-calipso.larc.nasa.gov/). Consistently, the monthly mean profile derived from ground-based lidar observations performed in M'Bour also shows the presence of a high altitude dust layer from 2 to $5 \mathrm{~km}$ (Léon et al., 2009). These consistent observations from two independent sensors suggest that the model reproduces correctly the high altitude transport of this Saharan dust event.

\section{Conclusions}

In this work, we tested the capability of the CHIMEREDUST model to reproduce the atmospheric dust load over the Sahelian region, especially its spatial and temporal distribution from the seasonal to the daily and event time scale. Several comparisons have been conducted, mainly based on a large data set of AOD and $\mathrm{PM}_{10}$ surface concentrations available for the year 2006 over an east-western transect located between 13 and $14^{\circ} \mathrm{N}$. In addition to the comparison of the simulations with satellite images and time series of measurements, the level of agreement between the simulations and 


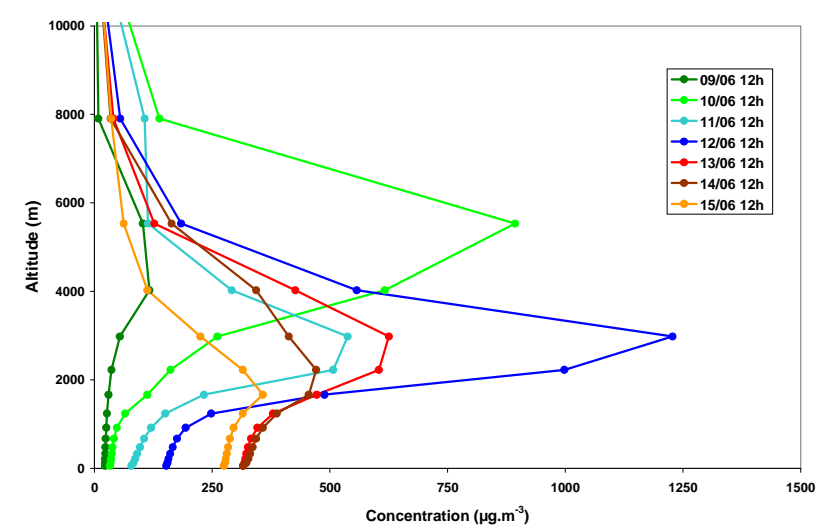

Fig. 19. Vertical distribution of the simulated mass concentration in Banizoumbou (Niger) in June 2006.

the measurements have been quantified using statistical indicators classically used to evaluate the performances of air quality models.

The simulated AODs and surface concentrations exhibit the same range of variations than the observed one. They also display similar temporal patterns than the measurements for the year 2006. The seasonal cycle of the AODs and surface concentration are correctly simulated at the regional scale. The level of agreement between the measured and simulated daily surface concentrations and hourly AOD can be considered as satisfying. The simulations and observations are significantly correlated at the different time-scale of comparison. The main bias of the simulations is a trend of underestimation for both the AODs and the surface concentrations. The mean errors are quite large, especially for the concentrations, suggesting the need for further improvement of the simulations. However, the mean errors and biases for the AODs and the surface concentrations are comparable to those provides by air quality models for the simulation of $\mathrm{PM}_{10}$ concentration. This reflects comparable difficulties for the simulation of coarse aerosol distributions both in natural and urban environments.

The largest discrepancies between the simulations and the observations correspond to late autumn and winter dust events originating from the Bodélé Depression. These discrepancies are either strong underestimations (in January) or strong overestimations of both the AODs and the surface concentrations. This highlights the necessity to further improve the representation of the surface wind fields in this region, accounting for seasonal variations in the wind pattern.

The occurrence and timing of specific dust events are correctly reproduced and also the order of magnitude of the measured AODs and surface concentrations, which is quite challenging since the station are located relatively close to the Saharan dust source regions. It was also shown that the model is able to reproduce the contrasted vertical distribution observed between late winter (low layer transport) and early summer (high altitude transport). However, different levels of agreement with the measured AODs and surface concentrations at some period of the year suggest some possible bias in the representation of the dust vertical distribution that would require a systematic comparison with measured vertical dust profiles.

If the temporal pattern and spatial distribution of the Saharan dust sources are realistically simulated, the intensity of the simulated emissions remains questionable since no direct quantitative observations are available to check their reliability. The simulated dust emissions are significantly higher than those previously published for the Sahara. In particular, they differ by a factor 3 with those published by Laurent et al. (2008) using the same dust emission scheme. We show that the difference on the simulated dust emissions mainly comes from the forcing surface wind fields, the operational ECMWF meteorological fields including higher surface winds, exceeding more frequently the erosion threshold than in the ERA-40 data base. A specific analysis of the quality and accuracy of the surface wind fields produced by different meteorological models or model versions (i.e. analysis versus operational products) compared to observations should be performed to provide a realistic forcing by surface winds over the Sahara. Such an analysis would be a key issue to improve the mineral dust emission over the Sahara and its transport toward the Sahel to the Atlantic Ocean and to the Mediterranean Sea.

Despite this high emission rate, the order of magnitude of both the simulated surface concentrations and aerosol optical thickness are consistent with the measurements available from Niger to Senegal. This indicated that the simulated regional dust budget remains largely under-constrained, the high emission being potentially compensated by too high deposition fluxes or poor representation of the vertical dust distributions. These results highlight the need for further and deeper validation on the vertical distribution, the dust size distribution and the deposition fluxes.

Acknowledgements. Based on a French initiative, AMMA was built by an international scientific group and is currently funded by a large number of agencies, especially from France, UK, US and Africa. It has been the beneficiary of a major financial contribution from the European Community's Sixth Framework Research Programme. The work was supported by the "Institut National des Sciences de l'Univers" (INSU/CNRS). We acknowledge the mission scientists and Principal Investigators who provided the satellite data used in this research effort. The analysis and visualizations of these data (Figs. 6, 7, 8) were produced with the Giovanni online data system, developed and maintained by the NASA GES DISC (Acker and Leptoukh, 2007) (http://disc.sci.gsfc.nasa.gov/giovanni/).

Edited by: X. Querol 


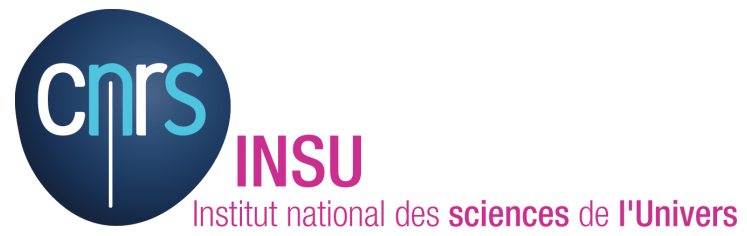

The publication of this article is financed by CNRS-INSU.

\section{References}

Acker, J. G. and Leptoukh, G.: Online Analysis Enhances Use of NASA Earth Science Data, Eos, Trans. AGU, 88(2), 14-17, 2007.

Alfaro, S. C. and Gomes, L.: Modeling mineral aerosol production by wind erosion: Emission intensities and aerosol distributions in source areas, J. Geophys. Res, 106, 18075-18084, 2001.

Alfaro, S. C., Rajot, J. L., and Nickling, W.: Estimation of PM20 emissions by wind erosion: Main sources of uncertainties, Geomorphology, 59, 63-74, 2004.

Bessagnet, B., Hodzic, A., Vautard, R., Beekmann, M., Cheinet, S., Honoré, C., Liousse, C., and Rouil, L.: Aerosol modeling with CHIMERE - preliminary evaluation at the continental scale, Atmos. Environ., 38, 2803-2817, 2004.

Borrego, C., Monteiro, A., Ferreira, J., Miranda, A. I., Cosat, A. M., Carvalho, A. C., and Lopes M.: Procedures for estimation of modelling uncertainty in air quality assessment, Environ. Int., 34, 613-620, 2008.

Bou Karam, D., Flamant, C., Tulet, P., Todd, M. C., Pelon, J., and Williams, E.: Dry cyclogenesis and dust mobilization in the intertropical discontinuity of the West African Monsoon: A case study, J. Geophys. Res., 114, D05115, doi:10.1029/2008JD010952, 2009.

Bouet, C., Cautenet, G., Washington, R., Todd, M. C., Laurent, B., Marticorena, B., and Bergametti, G.: Mesoscale modeling of aeolian dust emission during the BoDEx 2005 experiment, Geophys. Res. Lett., 34, L07812, doi:10.1029/2006GL029184, 2007.

Boylan J. W. and Russel A. G.: PM and light extinction model performance metrics, goals, and criteria for three-dimensional air quality models, Atmos. Environ., 40, 4946-4959, 2006.

Brooks, N. P. J. and Legrand, M.: Dust variability over northern Africa and rainfall in the Sahel, in: Linking climate change to landsurface change, edited by: McLaren, S. J. and Kniveton, D., Chapter 1, Kluwer Academic Publishers, 1-25, 2000.

Cakmur, R. V., Miller, R. L., Perlwitz, J., Geogdzhayev, I. V., Ginoux, P., Koch, D., Kohfeld, K. E., Tegen, I., and Zender, C. S.: Constraining the magnitude of the global dust cycle by minimizing the difference between a model and observations, J. Geophys. Res., 111, D06207, doi:10.1029/2005JD005791, 2006.

Callot, Y., Marticorena, B., and Bergametti, G.: Geomorphologic approach for modelling the surface features of arid environments in a model of dust emissions: application to the Sahara desert, Geodin. Acta, 13, 245-270, 2000.

Cavalieri, O., Di Donfrancesco, G., Cairo, F., Fierli, F., Snels, M., Viterbini, M., Cardillo, F., Chatenet, B., Formenti, P., Marticorena, B., and Rajot, J. L.: The AMMA mulid network for aerosol characterization in West Africa, Int. J. Remote Sens., doi:10.1080/01431161.2010.502156, in press, 2011.
d'Almeida, G. A.: A model for Saharan dust transport, J. Clim. Appl. Meteorol., 25, 903-916, 1986.

d'Almeida, G. A. and Schütz, L.: Number, mass and volume distributions, of mineral aerosols and soils of Sahara, J. Clim. Appl. Meteorol., 22, 233-243, 1983.

Dentener, F. J., Carmichael, G. R., Zhang, Y., Lelieveld, J., and Crutzen, P.: The role of mineral aerosol as a reactive surface in the global troposphere; J. Geophys. Res., 101, 22869-22889, 1996.

Flamant, C., Chaboureau, J.-P., Parker, D. J., Taylor, C., Cammas, J.-P., Bock, O., Timouk, F., and Pelon, J.: Airborne observations of the impact of a convective system on the planetary boundary layer thermodynamics and aerosol distribution in the intertropical discontinuity region of the West African Monsoon, Q. J. Roy. Meteorol. Soc., 133, 1175-1189, 2007.

Forêt, G., Bergametti, G., Dulac, F., and Menut, L.: An optimized particle size bin scheme for modelling mineral dust aerosols, J. Geophys. Res., 111, D17310, doi:10-1029/2005JD006797, 2006.

Ginoux, P., Chin, M., Tegen, I., Prospero, J., Holben, B., Dubovik, O., and Lin, S.-J.: Sources and distributions of dust aerosols simulated with the GOCART model, J. Geophys. Res., 106, 2025520273, doi:10.1029/2000JD000053, 2001.

Guelle, W., Balkanski, Y., Schulz, M., Marticorena, B., Bergametti, G., Moulin, C., Arimoto, R., and Perry, K. D.: Modeling the atmospheric distribution of mineral aerosol: comparison with ground measurements and satellite observations for yearly and synoptic time scales over the North Atlantic, J. Geophys. Res., 105, 1997-2001, 2000.

Heinold, B., Helmert, J., Hellmuth, O., Wolke, R., Ansmann, A., Marticorena, B., Laurent, B., and Tegen, I.: Regional modeling of Saharan dust events using LM-MUSCAT: Model description and case studies, J. Geophys. Res., 112, D11204, doi:10.1029/2006JD007443, 2007.

Herman, J. R., Bhartia, P. K., Torres, O., Hsu, C., Seftor C., and Celarier, E.: Global distribution of UV-absorbing aerosols from Nimbus 7/TOMS data, J. Geophys. Res., 102, 16911-16922, 1997.

Holben, B. N., Tanre, D., Smirnov, A., Eck, T. F., Slutsker, I., Abuhassan, N., Newcomb, W. W., Schafer, J., Chatenet, B., Lavenu, F., Kaufman, Y., Van de Castle, J., Setzer, A., Markham, B., Clark, D., Frouin, R., Halthore, R., Karnieli, A., O’Neill, N. T., Pietras, C., Pinker, R. T., Voss, K., and Zibordi, G.: An emerging ground-based aerosol climatology: Aerosol Optical Depth from AERONET, J. Geophys. Res., 106, 12067-12098, 2001.

Hsu, N. C., Tsay, S.-C., King, M. D., and Herman, J. R.: Aerosol properties over bright-reflecting source regions, IEEE T. Geosci. Remote, 42(3), 557-569, 2004.

Hsu, N. C., Tsay, S.-C., King, M. D., and Herman, J. R.: Deep blue retrievals of Asian aerosol properties during ACE-Asia, IEEE T. Geosci. Remote, 44(11), 3180-3195, 2006.

Intergovernmental Panel on Climate Control (IPCC): Climate Change 2007: The Physical Basis, in: Changes in Atmospheric Constituents and in Radiative Forcing, the Fourth, Assessment Report of the IPCC, edited by: Forster, P., Ramaswamy, V., Artaxo, R., Berntsen, T. Betts, R., Fahey, D. W., Haywood, J., Lean, J., Lowe, D. C., Myhre, G., Nganga, J., Prinn, R., Raga, G., Schulz, M., and Van Dorland, R., Cambridge University Press, Cambridge, United Kingdom and New York, NY, USA, 2007. 
Jaenicke R. and Schütz, L.: Comprehensive study of physical and chemical properties of the surface aerosols in Cape Verde Islands region, J. Geophys. Res., 83, 3585-3599, 1978.

Jickells, T. D., An, Z. S., Andersen, K. K., Baker, A. R., Bergametti, G., Brooks, N., Cao, J. J., Boyd, P. W., Duce, R. A., Hunter, K. A., Kawahata, H., Kubilay, N., La Roche, J., Liss, P. S., Mahowald, N., Prospero, J. M., Ridgwell, A. J., Tegen, I., and Torres, R.: Global iron connections: Between desert dust, ocean biogeochemistry and climate, Science, 308, 67-71, 2005.

Koren, I. and Kaufman, Y. J.: Direct wind measurements of Saharan dust events from Terra and Aqua satellites, Geophys. Res. Lett., 31, L06122, doi:10.1029/2003GL019338, 2004.

Laurent, B., Marticorena, B., Bergametti, G., Léon, J. F., and Mahowald, N. M.: Modeling mineral dust emissions from the Sahara desert using new surface properties and soil database, J. Geophys. Res., 113, D14218, doi:10.1029/2007JD009484, 2008.

Legrand, M., N'Doumé, C., and Jankowiak, I.: Satellite-derived climatology of the Saharan Aerosol, in: Passive Infrared Remote Sensing of Clouds and the Atmosphere II: proc. SPIE 2309, edited by: Lynch, D. K., 127-135, 1994.

Léon, J.-F., Derimian, Y., Chiapello, I., Tanré, D., Podvin, T., Chatenet, B., Diallo, A., and Deroo, C.: Aerosol vertical distribution and optical properties over M'Bour $\left(16.96^{\circ} \mathrm{W} ; 14.39^{\circ} \mathrm{N}\right)$, Senegal from 2006 to 2008, Atmos. Chem. Phys., 9, 9249-9261, doi:10.5194/acp-9-9249-2009, 2009.

Loosmore, G. and Cederwall, R.: Precipitation scavenging of atmospheric aerosols for emergency response applications: Testing an updated model with new real-time data, Atmos. Environ., 38, 993-1003, 2004.

Luo, C., Mahowald, N. M., and del Corral, J.: Sensitivity study of meteorological parameters on mineral aerosol mobilization, transport, and distribution, J. Geophys. Res., 108(D15), 4447, doi:10.1029/2003JD003483, 2003.

Mahowald, N. M., Jickells, T. D., Baker, A. R., Artaxo, P., BenitezNelson, C., Bergametti, G., Bond, T. C., Chen, Y., Cohen, D. D., Heruk, B., Kubilay, N., Losno, R., Luo, C., Maenhaut, W., Mc Gee, K. A., Okin, G., Seifert, R. L., and Tsukuda, S.: The global distribution of atmospheric phosphorus deposition and anthropogenic impacts, Global Biogeochem. Cy., 22, GB4026, doi:10.1029/2008GB003240, 2008.

Manabe, Y. and Gotlieb, J.: Nitrate formation on sea-salt and mineral particles - a single particle approach, Atmos. Environ., 26A, 1763-1769, 1992.

Marticorena, B. and Bergametti, G.: Modelling the atmospheric dust cycle: 1. Design of a soil derived dust production scheme, J. Geophys. Res., 100, 16415-16430, 1995.

Marticorena, B. and Bergametti, G.: Two-year simulations of seasonal and interannual changes of the Saharan dust emissions, Geophys. Res. Lett., 23, 1921-1924, 1996.

Marticorena, B., Bergametti, G., Aumont, B., Callot, Y., N'Doumé, C., and Legrand, M.: Modeling the atmospheric dust cycle: 2Simulations of Saharan dust sources, J. Geophys. Res., 102, 4387-4404, 1997.

Marticorena, B., Chatenet, B., Rajot, J. L., Traoré, S., Coulibaly, M., Diallo, A., Koné, I., Maman, A., NDiaye, T., and Zakou, A.: Temporal variability of mineral dust concentrations over West Africa: analyses of a pluriannual monitoring from the AMMA Sahelian Dust Transect, Atmos. Chem. Phys., 10, 8899-8915, doi:10.5194/acp-10-8899-2010, 2010.
Menut, L.: Adjoint modelling for atmospheric pollution processes sensitivity at regional scale during the ESQUIF IOP2, J. Geophys. Res., 108, 8562, doi:10.1029/2002JD002549, 2003.

Menut, L., Forêt, G., and Bergametti, G.: Sensitivity of mineral dust concentrations to the model size distribution accuracy, J. Geophys. Res., 112, D10210, doi:10.1029/2006JD007766, 2007.

Menut, L., Chiapello, I., and Moulin, C.: Predictability of mineral dust concentrations: The African Monsoon Multidisciplinary Analysis first short observation period forecasted with CHIMERE-DUST, J. Geophys. Res., 114, D07202, doi:10.1029/2008JD010523, 2009.

Miller, R. L., Perlwitz, J., and Tegen, I.: Feedback upon dust emission by dust radiative forcing through the planetary boundary layer, J. Geophys. Res., 109, D24209, doi:10.1029/2004JD004912, 2004.

Moulin, C., Lambert, C. E., Dulac, F., and Dayan, U., Control of atmospheric export of dust from North Africa by the North Atlantic Oscillation, Nature, 387, 691-694, 1997.

Moulin, C., Gordon, H. R., Banzon, V. F., and Evans, R. H.: Assessment of Saharan dust absorption in the visible from SeaWiFS imagery, J. Geophys. Res., 106(D16), 18239-18249, doi:10.1029/2000JD900812, 2001.

N'Tchayi, G. M., Bertrand, J., Legrand, M., and Baudet, J.: Temporal and spatial variations of the atmospheric dust loading throughout West Africa over the last thirty years, Ann. Geophys., 12, 265-273, doi:10.1007/s00585-994-0265-3, 1994.

Prospero, J. M. and Nees, R. T.: Dust concentration in the atmosphere of the Equatorial North Atlantic: possible relationship to the Sahelian drought, Science, 196, 1196-1198, 1977.

Prospero, J. M. and Nees, R. T.: Impact of the north African drought and El Nino on mineral dust in the Barbados trade winds, Nature, 320, 735-738, 1986.

Prospero, J. M., Ginoux, P., Torres, O., Nicholson, S. E., and Gill, T. E.: Environmental characterization of global sources of atmospheric soil dust identified with the Nimbus 7 Total Ozone Mapping Spectrometer (TOMS) absorbing aerosol product, Rev. Geophys., 40(1), 1-31, 2002.

Redelsperger, J. L., Thorncroft, C. D., Diedhiou, A., Lebel, T., Parker, D. J., and Polcher, J.: African Monsoon Multidisciplinary Analysis An International Reasearch Project and Field Campaign, B. Am. Meteor. Soc.., 87(12), 1739, doi:10.1175/BAMS87-12-1739, 2006.

Schepanski, K., Tegen, I., Todd, M. C., Heinold, B., Bönisch, G., Laurent, B., and Macke, A.: Meteorological processes forcing Saharan dust emission inferred from MSG]SEVIRI observations of subdaily dust source activation and numerical models, J. Geophys. Res., 114, D10201, doi:10.1029/2008JD010325, 2009.

Slingo, A., Ackerman, T. P., Allan, R. P., Kassianov, E. I., McFarlane, S. A., Robinson, G. J., Barnard, J. C., Miller, M. A., Harries, J. E., Russell, J. E., and Dewitte, S.: Observations of the impact of a major Saharan dust storm on the atmospheric radiation balance, Geophys. Res. Lett., 33, L24817, doi:10.1029/2006GL027869, 2006.

Slingo, A., Bharmal, N. A., Robinson, G. J., Settle, J. J., Allan, R. P., White, H. E., Lamb, P. J., Issa Lélé, M., Turner, D. D., McFarlane, S., Kassianov, E., Barnard, J., Flynn, C., and Miller, M.: Overview of observations from the RADAGAST experiment in Niamey, Niger. Part 1: Meteorology and thermodynamic variables, J. Geophys. Res, 113, D00E01, 
doi:10.1029/2008JD009909, 2008.

Slinn, W. G. N.: Precipitation scavenging, in: Atmospheric Science and Power Production, edited by: Randerson, D., OSTI, Oak Ridge, 466-532, 1984.

Sokolik, I., Winker, D., Bergametti, G., Gillette, D. A., Carmichael, G., Kaufman, Y., Gomes, L., Schütz, L., and Penner, J.: Outstanding problems in quantifying the radiative impact of mineral dust, J. Geophys. Res., 106, 18075-18084, 2001.

Stanelle, T., Vogel, B., Vogel, H., Bäumer, D., and Kottmeier, C.: Feedback between dust particles and atmospheric processes over West Africa during dust episodes in March 2006 and June 2007, Atmos. Chem. Phys., 10, 10771-10788, doi:10.5194/acp10-10771-2010, 2010.

Tegen, I. and Fung, I.: Modeling of mineral dust in the atmosphere: Sources, transport, and optical thickness, J. Geophys. Res., 99, 22897-22914, 1994.

Tegen, I. and Lacis, A.: Modeling of particle size distribution and its influence on the radiative properties of mineral dust aerosol, J. Geophys. Res., 101, 19237-19244, 1996.

Tegen, I., Heinold, B., Todd, M., Helmert, J., Washington, R., and Dubovik, O.: Modelling soil dust aerosol in the Bodélé depression during the BoDEx campaign, Atmos. Chem. Phys., 6, 43454359, doi:10.5194/acp-6-4345-2006, 2006.

Torres, O., Bhartia, P. K., Herman, J. R., Ahmad, Z., and Gleason, J.: Derivation of aerosol properties from satellite measurements of backscattered ultraviolet radiation: Theoretical basis, J. Geophys. Res., 103, 17099-17110, 1998.

Tulet, P., Mallet, M., Pont, V., Pelon, J., and Boone, A.: The 713 March 2006 dust storm over West Africa: Generation, transport, and vertical stratification, J. Geophys. Res., 113, D00C08, doi:10.1029/2008JD009871, 2008.
United States Environmental Protection Agency (US EPA), Guidance on the Use of Models and Other Analyses for Demonstrating Attainment of Air Quality Goals for Ozone, $\mathrm{PM}_{2.5}$, and Regional Haze, Office of Air Quality Planning and Standards, Air Quality Analysis Division, Air Quality Modeling Group, US EPA, Research Triangle Park, NC, USA; EPA-454/B-07-002, April 2007.

Van Leer, B.: Towards the ultimate conservative difference scheme.V A second order sequel to Godunov's method, J. Comput. Phys., 32, 101-136, 1979.

Vautard, R., Beekmann, M., Roux, J., and Gombert, D.: Validation of a deterministic forecasting system for the ozone concentrations over the Paris area, Atmos. Environ., 35, 2449-2461, 2001.

Venkatram, A. and Pleim, J.: The electrical analogy does not apply to modeling dry deposition of particles, Atmos. Environ., 33, 3075-3076, 1999.

Washington, R., Todd, M. C., Engelstaedter, S., M'Bainayel, S., and Mitchell, F.: Dust and the low-level circulation over the Bode'le' Depression, Chad: Observations from BoDEx 2005, J. Geophys. Res., 111, D03201, doi:10.1029/2005JD006502, 2006.

Wesely, M. L.: Parameterizations of surface resistance to gaseous dry deposition in regional-scale numerical models, Atmos. Environ., 23, 1293-1304, 1989.

Wu, P.-M. and Okada, K.: Nature of the coarse nitrate particles in the atmosphere - A single particle approach, Atmos. Environ., 28, 2053-2060, 1994.

Yoshioka, M., Mahowald, N., Dufresne, J. L., and Luo, C.: Simulation of absorbing aerosol indices for African dust, J. Geophys. Res., 110, D18S17, doi:10.1029/2004JD005276, 2005.

Zhao, D., Xiong, J., Xu, Y., and Chan, W. H.: Acid rain in southern China, Atmos. Environ., 22, 349-358, 1988. 